\title{
Modulation of Hypercholesterolemia-Induced Oxidative/Nitrative Stress in the Heart
}

\author{
Csaba Csonka, Márta Sárközy, Márton Pipicz, László Dux, and Tamás Csont \\ Department of Biochemistry, Faculty of Medicine, University of Szeged, Dóm tér 9, Szeged 6720, Hungary
}

Correspondence should be addressed to Tamás Csont; csont.tamas@med.u-szeged.hu

Received 14 August 2015; Accepted 16 September 2015

Academic Editor: Luciano Saso

Copyright (C) 2016 Csaba Csonka et al. This is an open access article distributed under the Creative Commons Attribution License, which permits unrestricted use, distribution, and reproduction in any medium, provided the original work is properly cited.

\begin{abstract}
Hypercholesterolemia is a frequent metabolic disorder associated with increased risk for cardiovascular morbidity and mortality. In addition to its well-known proatherogenic effect, hypercholesterolemia may exert direct effects on the myocardium resulting in contractile dysfunction, aggravated ischemia/reperfusion injury, and diminished stress adaptation. Both preclinical and clinical studies suggested that elevated oxidative and/or nitrative stress plays a key role in cardiac complications induced by hypercholesterolemia. Therefore, modulation of hypercholesterolemia-induced myocardial oxidative/nitrative stress is a feasible approach to prevent or treat deleterious cardiac consequences. In this review, we discuss the effects of various pharmaceuticals, nutraceuticals, some novel potential pharmacological approaches, and physical exercise on hypercholesterolemia-induced oxidative/nitrative stress and subsequent cardiac dysfunction as well as impaired ischemic stress adaptation of the heart in hypercholesterolemia.
\end{abstract}

\section{Introduction}

Hypercholesterolemia, a frequent form of hyperlipidemia, is a metabolic disorder characterized by elevated levels of total cholesterol in the blood. Hypercholesterolemia may develop as a consequence of unbalanced diet, obesity, inherited (genetic) diseases (familial hypercholesterolemia), or other diseases (e.g., diabetes). According to large clinical studies, hypercholesterolemia affects a significant population of adults in developed countries [1]. For instance, approximately 100 million people (44.4\%) suffered from hypercholesterolemia $(>5.2 \mathrm{mmol} / \mathrm{L})$ in the United States in 2008 [2]. The relationship between hypercholesterolemia and cardiovascular mortality has been known for decades [3]. Hypercholesterolemia, especially elevated low density lipoprotein (LDL) cholesterol, is a major risk factor for the development of atherosclerosis and subsequent ischemic heart disease [4], which is a leading cause of death worldwide [5]. Moreover, several experimental studies have demonstrated that, in addition to its well-known proatherogenic effect in the vasculature, hypercholesterolemia may directly affect the heart causing contractile dysfunction [6-8], aggravated ischemia/reperfusion injury [9], and attenuated responses to cardioprotective interventions including ischemic preand postconditioning $[10,11]$. Although the pathoetiology of hypercholesterolemia has been studied extensively, the precise molecular mechanisms leading to cardiac complications are not entirely clear. Nevertheless, substantial evidence exists demonstrating that hypercholesterolemia induces oxidative and nitrative stress in the heart and that oxidative/nitrative stress plays a role in several cardiac pathologies. Therefore, modulation of oxidative stress in the hypercholesterolemic myocardium appears to be a rational approach. In this review we aim to discuss relevant literature related to potential modulation of hypercholesterolemia-induced oxidative stress and subsequent complications in the heart (Figure 1). Our attention is focused on certain pharmaceuticals, nutraceuticals, novel pharmacological approaches, and physical exercise as potential modulators.

\section{Hypercholesterolemia and Oxidative/Nitrative Stress}

Oxidative/nitrative stress can be defined as an excess formation or insufficient removal of highly reactive molecules such as reactive oxygen and/or nitrogen species (ROS and 


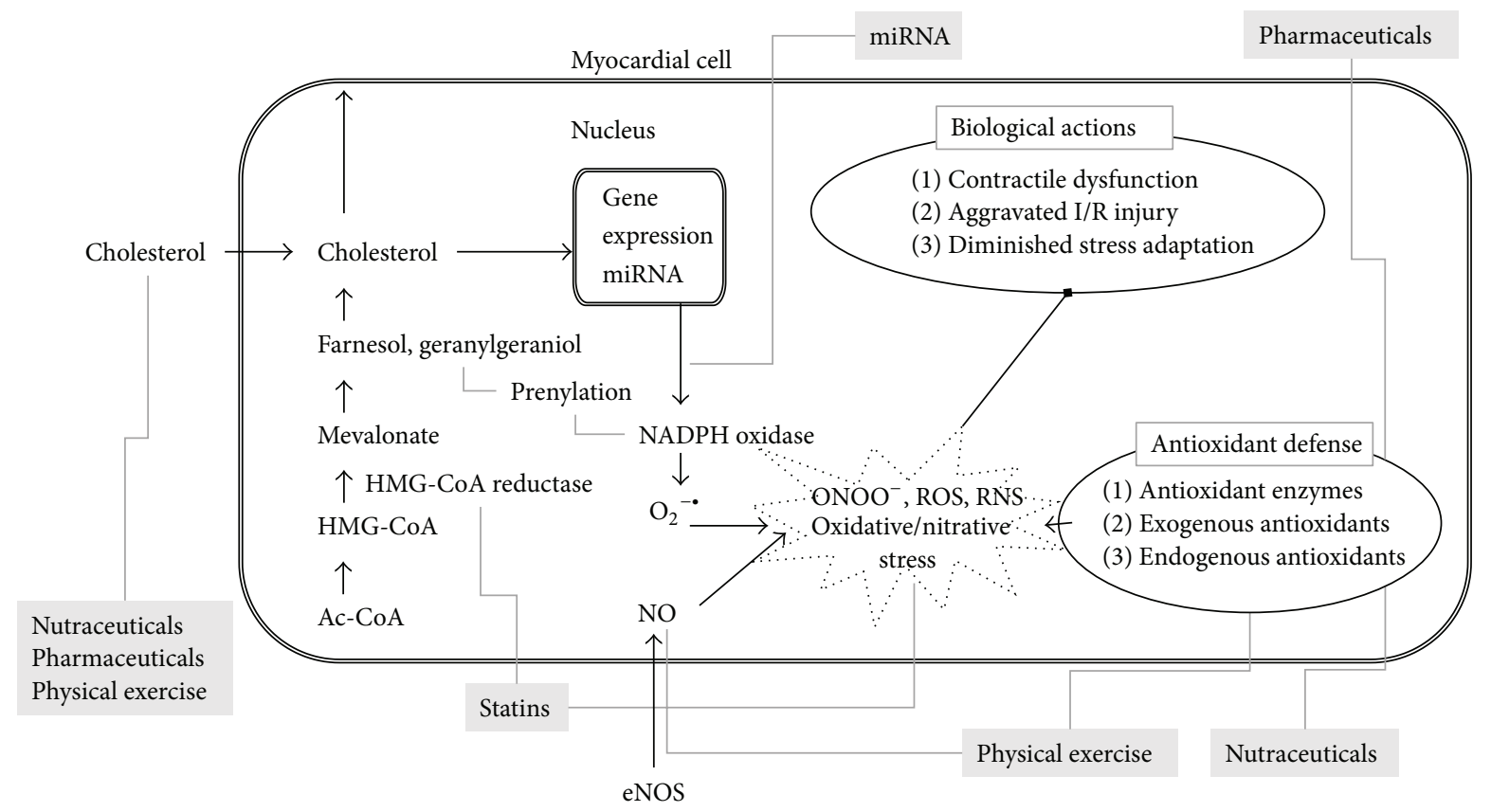

FIGURE 1: Hypercholesterolemia-induced myocardial oxidative/nitrative stress and its possible modulations (in grey boxes) to prevent or treat deleterious cardiac consequences. Ac-CoA: acetyl-coenzyme A; HMG-CoA: 3-hydroxy-3-methyl glutaryl coenzyme A; eNOS: endothelial nitric oxide synthase; $\mathrm{ONOO}^{-}$: peroxynitrite; ROS: reactive oxygen species; RNS: reactive nitrogen species; miRNA: microRNA.

RNS, resp.) including, for instance, superoxide, hydrogen peroxide, hydroxyl radical, and peroxynitrite [12]. Enzymatic sources for ROS formation include the mitochondrial respiratory chain, nicotinamide adenine dinucleotide phosphate (NADPH) oxidases, xanthine oxidase, cyclooxygenases, uncoupled nitric oxide synthase (NOS), and peroxidases, while antioxidant enzymatic systems include superoxide dismutase (SOD), catalase, glutathione peroxidase, glutathione reductase, and heme oxygenase (HO) [13]. Although there is a consensus in the literature that hypercholesterolemia is associated with increased cardiac oxidative stress (Figure 1), the precise molecular mechanisms by which hypercholesterolemia induces oxidative stress in the heart are not entirely clear. Accumulating evidence shows increased superoxide production in the hearts of hypercholesterolemic animals, and one of the major sources of this superoxide appears to be increased NADPH oxidase activity in cholesterol-fed Wistar rats and apoB100 transgenic mice $[6,8]$. In the hearts of cholesterol-fed CFLP mice and Wistar rats, transcript levels of NADPH oxidase 4 (NOX4) were significantly increased when compared to normal controls fed a standard chow $[8,14]$. The increased NOX4 transcript levels in hypercholesterolemic hearts can be related to transcriptional, posttranscriptional, or epigenetic regulation of NOX4 expression. One study shows an association of cardiac NOX4 transcript and protein levels as well as NADPH oxidase activity with decreased myocardial level of the microRNA miR-25 in rats with diet-induced hypercholesterolemia [8]. MicroRNAs (miR or miRNA) are endogenous, small, noncoding RNAs that are responsible for posttranscriptional silencing of a wide variety of specific target genes. NOX4 was identified as a direct target of miR-25, suggesting that decreased miR25 allows the upregulation of NOX4, which contributes to increased ROS production in the hypercholesterolemic heart [8]. Although alterations in cardiac gene expression have been demonstrated in animal models of diet-induced hypercholesterolemia $[14,15]$ and metabolic syndrome [16], to the best of our knowledge, the precise molecular link between hypercholesterolemia and altered cardiac gene expression has not yet been elucidated. Interestingly, two key transcriptional factors have been implicated to date in cholesterol-dependent transcriptional regulation of gene expression, that is, the sterol-regulatory element binding protein (SREBP) and the liver X receptor (LXR) [17]; however, direct evidence for their role in hypercholesterolemia-induced oxidative stress is still lacking.

Another possible explanation for increased oxidative stress could be diminished endogenous antioxidant capacity. Indeed, hypercholesterolemia has been reported to be associated with decreased cardiac expression and activity of antioxidant enzymes [18-21]. Nevertheless, the precise molecular mechanisms by which high cholesterol downregulates myocardial antioxidant enzymes remain to be elucidated. Besides enzymatic mechanisms, tissue level of the endogenous antioxidants is also an important determinant of oxidative/nitrative stress. Nitric oxide (NO) is a key antioxidant molecule that is synthesized by NO synthases in various cells including cardiomyocytes. In the hearts of hypercholesterolemic animals, cardiac NO level was decreased when compared to controls [10, 22, 23]; however, this effect was independent of the modulatory effect of cholesterol on the mevalonate pathway [23]. Moreover, transcript levels of NOS 
3 were decreased, while NOS 1 and 2 remained unaffected in the hearts of cholesterol-fed mice [14].

In addition to the effects of cholesterol and its derivatives on gene expression, membrane-related effects of cholesterol are also plausible [39]; however, these effects have barely been investigated in the hypercholesterolemic heart.

\section{Functional Effects of Hypercholesterolemia on the Heart}

Hypercholesterolemia has been shown to exert direct myocardial effects independent of the development of atherosclerosis in both clinical $[40,41]$ and preclinical studies $[7,8]$. These effects include impaired cardiac performance and contractile dysfunction [6, 7], aggravated ischemia/reperfusion injury [9], and diminished adaptation to ischemic stress $[10,11,42]$ (Figure 1).

3.1. Cardiac Contractile Dysfunction. Observations in human clinical trials and animal models suggest a direct effect of cholesterol on myocardial contractile function leading to impaired diastolic and in some cases also systolic function [6$8,43-45]$. Although the symptoms of hypercholesterolemia are not pronounced initially and the disorder may be dormant for a long time, preclinical diastolic dysfunction shows a clear progression to heart failure [46]. Development of heart failure aggravates with advancing age and contributes to age-related morbidity and mortality [47].

The direct effects of cholesterol exposure on cardiomyocyte function were demonstrated in a cell culture model; that is, elevation of membrane cholesterol content in ventricular cardiomyocytes resulted in decreased cytosolic calcium levels and impaired cardiac myocyte contractility [48]. This has been confirmed in cholesterol-fed rabbits and rats, showing apparent contractile dysfunction characterized by decreased maximum rate of shortening, decreased rate of relaxation, and increased left ventricular end-diastolic pressure $[7,8,10$, 44]. Moreover, impairment of cardiac performance assessed by measuring aortic flow was also demonstrated in hearts isolated from hypercholesterolemic apoB100 transgenic mice [6]. Hypercholesterolemia-induced cardiac dysfunction was further confirmed by echocardiography in humans $[43,45$, 49].

It has been shown previously that myocardial oxidative/nitrative stress induced by hypercholesterolemia significantly contributes to the development of cardiac dysfunction $[6,8,50]$. However, the exact underlying molecular mechanisms are still not entirely clear. One possible mechanism is the oxidation of contractile proteins $[8,51,52]$. In failing human heart samples, for instance, there is an obvious oxidation and nitrosylation of tropomyosin and actin, showing a positive correlation with diminished contractile function indicated as a decrease in ejection fraction [51]. Moreover, increased protein oxidation was confirmed in the hearts of hypercholesterolemic rats [8].

3.2. Aggravated Ischemia/Reperfusion Injury and Attenuated Stress Adaptation. Hypercholesterolemia facilitates the risk of atherosclerosis and subsequent myocardial infarction.
The current treatment of myocardial infarction includes the attempt to reopen the occluded coronary artery (termed reperfusion) in a timely manner by coronary intervention procedures or thrombolytic therapies in order to reduce infarct size, which is one of the major determinants of long term complications and survival. Thus the majority of patients with acute myocardial infarction undergo ischemia/reperfusion injury. However, the myocardium is remarkably good at adapting to ischemic conditions by triggering endogenous adaptive mechanisms against ischemia/reperfusion injury. One of the most powerful endogenous adaptive cardioprotective mechanisms is ischemic preconditioning, that is, when brief exposure to repetitive ischemia/reperfusion cycles markedly enhances the ability of the heart to withstand a subsequent, potentially lethal ischemic attack [53]. Another possible intervention is termed ischemic postconditioning when the initial phase of reperfusion is interrupted with short periods of ischemia [54]. In addition, remote conditioning has also been introduced when cardioprotection is achieved by exposing an organ at a distance from the heart to ischemia/reperfusion insults [55]. To date, a very large number of preclinical and clinical studies are available suggesting that hypercholesterolemia enhances the severity of ischemia/reperfusion injury and interferes with the endogenous cardioprotective mechanisms. The mechanisms of ischemia/reperfusion injury and endogenous cardioprotection as well as the effect of hypercholesterolemia on these phenomena have been extensively reviewed elsewhere [56-58].

\section{Modulation of Hypercholesterolemia- Induced Oxidative/Nitrative Stress}

Modulation of oxidative/nitrative stress in hypercholesterolemia can be approached by at least 3 different ways (Figure 1). First, cholesterol-lowering therapies should be effective in attenuation of oxidative/nitrative stress due to their trigger-eliminating effect. Second, the mechanism of action of several drugs used for cholesterol-lowering is complex and may involve antioxidant properties. The second approach may be the most obvious, that is, the application of antioxidant molecules and especially natural products to reduce oxidative/nitrative stress. Third, support or induction of endogenous enzymatic antioxidant systems or inhibition of the prooxidant enzymes may be a feasible way to control cardiac oxidative/nitrative stress in hypercholesterolemia. These distinct mechanisms of action are often combined in the case of certain modulators. In this section we discuss various pharmaceuticals, nutraceuticals, some novel approaches, and even physical exercise as potential modulators of hypercholesterolemia-induced oxidative/nitrative stress.

4.1. Pharmaceuticals. To the best of our knowledge, there are no drugs on the market approved to specifically target cardiac oxidative/nitrative stress induced by hypercholesterolemia. Nevertheless, cholesterol-lowering drugs are excessively prescribed for patients presenting hypercholesterolemia and due to their cholesterol-lowering effect they should have 
a secondary attenuating effect on hypercholesterolemiainduced oxidative/nitrative stress. Interestingly, several of these drugs have also been implicated in directly modulating oxidative/nitrative stress. Moreover, large clinical trials have shown that antihyperlipidemic agents, for example, statins [59], fibrates [60], and niacin [61], could reduce the incidence of cardiovascular events in hypercholesterolemic patients [59]. In addition, some drugs used for other indications than treatment of hypercholesterolemia (e.g., some antidiabetics and vasodilators) have also been demonstrated to attenuate hypercholesterolemia-induced oxidative/nitrative stress and deleterious cardiac consequences.

4.1.1. Statins. Statins are a class of cholesterol-lowering drugs that inhibit the key enzyme, 3-hydroxy-3-methylglutaryl coenzyme A (HMG-CoA) reductase, of the endogenous cholesterol biosynthesis. Statins have therefore become established in the treatment of hypercholesterolemia and attained a central place in cardiovascular medicine [62]. However, there are potential side effects of statin therapy including skeletal muscle complaints and/or mild elevation of serum creatine kinase level and very rarely rhabdomyolysis [63]. The main members of statins on the market are lovastatin, rosuvastatin, simvastatin, atorvastatin, fluvastatin, pravastatin, and the newest addition, pitavastatin. By inhibition of the formation of mevalonate, the direct reaction product of HMG-CoA reductase and HMG-CoA, statins not only inhibit the formation of the end-product, cholesterol, but also they reduce the formation of other cholesterol pathway intermediers such as the 15-carbon isoprenoid farnesol or the 20-carbon isoprenoid geranylgeraniol which finally lead to reductions in protein prenylation, Coenzyme Q10 (see later), and dolichol synthesis. Besides lipid-lowering effects, statins have pleiotropic effects on different cell types. Some of these cholesterol-independent effects of statins involve improved endothelial function, stabilization of atherosclerotic plaques, and attenuation of oxidative stress and inflammation as well as inhibition of the thrombogenic response $[64,65]$. Pleiotropic effects may play an important part in reducing cardiovascular mortality and morbidity and may act at multiple points in the complex cascade of events leading to atherosclerosis.

Regarding the antioxidative effect of statins, a recent study showed that, beside the cholesterol-lowering effect, simvastatin is able to ameliorate endothelial dysfunction through increasing NO bioavailability and through suppression of oxidative stress in a rat model of hypercholesterolemia [66]. Similar results were shown by Iliodromitis et al., [67] who found that a 3-week simvastatin treatment limits infarct size and attenuates oxidative and nitrosative stress both in normocholesterolemic and in hypercholesterolemic rabbits subjected to ischemia/reperfusion irrespective of the presence of postconditioning, while postconditioning was effective only in normocholesterolemic animals. According to another study [68], pravastatin, in contrast to samedose simvastatin or postconditioning, was found to reduce infarction in hypercholesterolemic rabbits independently of lipid-lowering, potentially through eNOS activation and attenuation of oxidative/nitrative stress. The antioxidative effect of atorvastatin was also shown by several studies [6972]. Moreover, in hyperlipidemic subjects with metabolic syndrome, atorvastatin is associated with a greater reduction in lipid markers of oxidation compared with pravastatin [73]. In contrast, Sodha et al. [74] found increased levels of myocardial biomarkers of oxidative stress in hypercholesterolemic swine treated with atorvastatin. Pitavastatin, the newest member of the HMG-CoA reductase inhibitor family, has shown improvements in both cardiovascular function and markers of oxidative stress [75], presumably via decreasing NADPH oxidase activation [64]. Fluvastatin was also shown to play a protective role against high-cholesterol-induced oxidative stress and DNA damage [76]. Taken together, the cardioprotective effect of almost every statin is associated with some pleiotropic effect which can decrease oxidative stress in the cardiovascular system.

4.1.2. Ezetimibe. Ezetimibe, another lipid-lowering drug, is used in monotherapy or in combination with statins and is responsible for lowering intestinal cholesterol absorption by inhibiting the Niemann-Pick C1-Like 1 (NPC1L1) sterol transporter. Clinical studies showed that ezetimibe attenuates the markers of oxidative stress in hyperlipidemic subjects [77-80]. The drug is suggested to exert both cholesteroldependent and independent actions [78-80]. Reduction of serum cholesterol results in decreased cholesterol influx to the cells thereby attenuating cholesterol-induced oxidative stress. For instance, ezetimibe reduced hepatic cholesterol level in obese male mice which in turn attenuated oxidative stress via downregulation of NADPH oxidases, cytochrome P4502E1, and beta oxidation [81]. In addition to its cholesterol-lowering action, ezetimibe may exert a direct cholesterol-independent effect on cells [78-80, 82]. A feasible explanation is that NPC1L1 is widely expressed in many other tissues including liver, kidney, muscle, and heart [83]. Cell culture studies support the possible direct effect of ezetimibe on cellular oxidative/nitrative stress, for example, knockdown of NPC1L1 in hepatocytes attenuated ROS production [84]. Based on these findings it is plausible to speculate that ezetimibe has a direct impact on the heart and may decrease cholesterol-induced oxidative stress. Nevertheless, direct cardioprotective effect of ezetimibe has not yet been investigated in the literature; thus preclinical studies needed to address this issue.

4.1.3. Niacin. Although niacin (nicotinic acid or Vit $\mathrm{B}_{3}$ ) is a potent lipid-lowering agent when used in pharmacologic doses, its clinical use is limited by side effects, so it can be applied particularly in combination to treat marked dyslipidemia with strict monitoring ([85], for review see [86]). Niacin administration was shown to reduce markers of serum oxidative stress and increase antioxidant paraoxonase1 in patients with hypercholesterolemia [87]. A randomized controlled clinical trial reported that niacin improves both 6and 15-year mortality of patients after myocardial infarction with or without metabolic syndrome thereby suggesting a cardioprotective effect for niacin [88]. Direct cardioprotective effect of niacin was reported in preclinical studies as well [89-92]. However, evidence is not available to clarify the 
potential beneficial effect of niacin in cholesterol-induced cardiac stress.

4.1.4. Fibrates. Fibrates (amphipathic carboxylic acid derivatives) lower plasma triglyceride and small LDL level and increase high density lipoprotein (HDL) concentration; thus fibrates are particularly used to treat combined dyslipidemia related to diabetes or metabolic syndrome [93]. This class of drugs acts on nuclear peroxisome proliferator-activated receptor $\alpha$ (PPAR $\alpha)$, leading to transcriptional changes [94]. Studies revealing the effect of fibrates on cholesterol-induced cardiac oxidative stress are not available in the literature. Nevertheless, some investigations have reported an antioxidant effect of fibrates. A subcohort clinical trial has demonstrated that 3-week fenofibrate treatment reduced ox-LDL and 8isoprostane, systemic markers of oxidative stress in patients with hypertriglyceridemia [95]. In accordance with these results, fenofibrate decreased ox-LDL with a modest reduction in cholesterol level in healthy normolipidemic older adults [96]. Fibrates may exert antioxidant actions independently from their lipid-lowering effect. For instance, Sugga et al. have reported that in vivo administration of fenofibrate and clofibrate before ex vivo myocardial ischemia/reperfusion reduced infarct size and oxidative stress [97]. Others have shown antioxidant and cardioprotective effects of fibrates against development of ventricular hypertrophy associated with oxidative stress $[98,99]$. Furthermore, fibrates prevent endothelial dysfunction by ameliorating oxidative stress, without affecting plasma lipid levels $[100,101]$. It has been also published that knockout of PPAR $\alpha$, the ligand of fibrates, leads to oxidative stress associated with cardiac dysfunction [102]. In contrast, fenofibrate failed to improve lipotoxic cardiomyopathy [103], and high dose fibrate induced cardiac damage in healthy rats [104]. Taken together, the studies focusing on antioxidant action of fibrates suggest a potential beneficial effect on cholesterol-induced cardiac oxidative stress, although this needs to be confirmed in further studies.

4.1.5. Other Pharmaceuticals. There are some available drugs, which are basically used to treat other diseases than hypercholesterolemia and which have beneficial effects on highcholesterol-induced cardiac consequences.

Rosiglitazone is an antidiabetic drug; however, it also improves blood cholesterol level in hypercholesterolemic models $[105,106]$. It was reported that the drug prevents the development of high-cholesterol-induced cardiac hypertrophy [105] and ameliorates postischemic recovery and nitrative stress in the heart of high-cholesterol-fed rabbits [107]. The latter research group has also shown that rosiglitazone alleviates aggravated postischemic myocardial injury and myeloperoxidase upregulation caused by hypercholesterolemia, independently from the lipid-lowering action [108]. Rosiglitazone has a direct antioxidant effect on cardiomyocytes [109] and has been demonstrated to prevent the upregulation of cardiac NOX4 in a high-fat highsugar diet, streptozotocin-induced diabetic model associated with dyslipidemia [110]. These findings make rosiglitazone a promising modulator of cholesterol-induced cardiac oxidative stress.
Increasing the level of glucagon-like peptide- 1 by administration of analogues or by inhibiting dipeptidyl peptidases is used for the treatment of diabetes and has recently emerged as a potential cardioprotective approach [111]. Specifically, a glucagon-like peptide-1 agonist was shown to reverse cardiac dysfunction induced by high-fat diet [112] and a dipeptidyl peptidase inhibitor was found to improve cardiac dysfunction and oxidative stress in high-fat high-fructose-fed mice [113].

The vasodilator fasudil (a potent rho kinase inhibitor) was shown to lower serum cholesterol level and decrease cardiac oxidative stress by enhancing antioxidants in hypercholesterolemic rat hearts [114]. The group has reported that fasudil restores cardiac eNOS and NO level diminished by high-cholesterol diet [114]. Interestingly, even in the state of hypercholesterolemia, fasudil can induce both preconditioning and postconditioning [115]. Moreover, fasudil restores the cardioprotective effect of ischemic postconditioning in rats with hypercholesterolemia [116].

4.2. Nutraceuticals. In spite of the extensive research in cardiology, particularly in ischemic heart diseases, only very few new cardioprotective drugs have found their way into clinical practice [117]. Therefore, there is a growing interest in nutraceuticals to treat and also prevent certain cardiac diseases or restore the injured adaptation of the heart. Nutraceuticals is a term that refers to a wide range of products including but not limited to natural herbal products, dietary supplements, isolated nutrients, and special diets. Since there is also a growing desire among potential customers to consume natural dietary products instead of chemically synthesized compounds, the importance of these nutraceuticals is being further emphasized.

Natural food substances have the potential to alter biological functions of the cells by mechanisms enhancing the endogenous antioxidant systems or through altering the redox signaling status of the cell. This is often related to the unique composition of different antioxidant compounds in the various nutraceuticals. These products could be beneficial in pathological conditions where oxidative stress plays an important role.

4.2.1. Antioxidant Vitamins. A number of preclinical studies have demonstrated that classical antioxidant vitamins including beta carotene (Vit A precursor), folic acid (Vit $\mathrm{B}_{9}$ ) vitamin $\mathrm{C}$, and vitamin $\mathrm{E}$ administered alone or in combination with other drugs or in multivitamin preparations could improve serum lipid profile and myocardial oxidative/nitrative stress in hypercholesterolemia $[18,118-$ 126]. Moreover, low dose beta carotene has been shown to improve cardiac function and reduce myocardial oxidative stress after ischemia/reperfusion injury in hearts of rats [63]. In contrast, vitamin $\mathrm{C}$ alone or combined with vitamin $\mathrm{E}$ failed to reduce myocardial infarct size in an open chest rabbit model [127]. Indeed, Trolox, a vitamin E analogue did not reduce infarct size but accelerated functional recovery after myocardial infarction in porcine hearts [128]. In addition, we have previously shown that a multivitamin preparation supplemented with phytosterols decreased serum cholesterol level in hypercholesterolemic rats; however, it did 
not reduce infarct size either in normocholesterolemic or in hypercholesterolemic hearts of rats [118]. In contrast, preconditioning with vitamin $\mathrm{E}$ has been shown to improve postischemic contractile and vascular functions in hearts of rats after ischemia/reperfusion injury [129]. To the best of our knowledge, the effects of antioxidant vitamins have not been tested on cardioprotection conferred by ischemic preor postconditioning. However, decrease of oxidative/nitrative stress by antioxidant vitamins could be a potential therapeutic target in the restoration of cardioprotective adaptive mechanisms lost in hypercholesterolemia.

Despite a number of preclinical studies proving beneficial effects of antioxidant vitamins on cardiac pathologies in hypercholesterolemia, clinical trials investigating the effects of antioxidant vitamins on cardiovascular morbidity and mortality have been disappointing. The complex reasons that might explain the translational failures of preclinical results into clinical therapy are discussed in detail in recent reviews [130-132] and include the following: (i) oxidative/nitrative stress is just a late consequence of cardiac pathologies and not the primary cause; (ii) pathogenesis of cardiovascular diseases is complex and increased oxidative/nitrative stress is not the only cause of these disorders; (iii) antioxidant vitamin therapy is not able to reduce oxidative/nitrative stress due to inappropriate study design (inappropriate patient selection, failure in the administration route, suboptimal time and duration of antioxidant therapy, poor target specificity, and potential interaction with other drugs, etc.); (iv) a single antioxidant therapy is not enough to overcome increased oxidative/nitrative stress; (v) antioxidant molecules might have harmful effects on physiological processes or compensatory mechanisms in pathologic conditions induced by oxidative/nitrative stress.

The lack of beneficial effects of antioxidant vitamins on cardiovascular pathologies in clinical trials does not disprove that oxidative/nitrative stress plays a crucial role in cardiac pathologies in hypercholesterolemia. These clinical trials challenge us to develop better antioxidant approaches and better preclinical models as well as to design more appropriate clinical trials considering the aforementioned reasons of translational failure.

4.2.2. Coenzyme Q. Coenzyme Q10 (CoQ10), also called ubiquinone or ubiquinol, is an isoprene derivative and an alternative product of the mevalonate/cholesterol pathway. CoQ10 is an endogenous nonenzymatic lipophilic antioxidant and free radical scavenging molecule playing a role in the mitochondrial electron transport in the inner mitochondrial membrane [133]. Moreover, CoQ10 has been reported to play part in many levels of the redox control of cellular signaling; in fact the autoxidation of its semiquinone form, generated in various membranes during electron transport, can be a primary source for hydrogen peroxide production, which activates transcription factors [134]. Due to its localization in the mitochondria, it plays a key role in the cellular bioenergetics especially in tissues with high energy requirements such as the myocardium which is extremely sensitive to CoQ10 deficiency $[133,135]$. CoQ10 has been shown to decrease the levels of proinflammatory cytokines and to reduce LDL oxidation and consequently the progression of atherosclerosis. It also decreased ischemia/reperfusion injury after myocardial infarction $[135,136]$. Significant improvement has been demonstrated in clinical and hemodynamic parameters and in exercise tolerance in patients given adjunctive CoQ10 in various trials conducted in patients suffering from heart failure, hypertension, ischemic heart disease, and other cardiac illnesses [135-137]. Therefore, CoQ10 could be a potential therapeutic molecule in heart diseases.

Due to the common biosynthetic pathway of cholesterol and CoQ10, the HMG-CoA reductase inhibitor statins may potentially reduce the levels of CoQ10 in different tissues [138]. Indeed, it has been reported that CoQ10 levels in the plasma, platelets, and lymphocytes were decreased after statin treatment [138]. Some papers indicated that CoQ10 depletion during statin therapy might be associated with subclinical cardiomyopathy and this situation is reversed upon CoQ10 treatment [138]. In contrast, a preclinical study reported that coadministration of CoQ10 with simvastatin impaired mitophagy and cardioprotection after ischemia/reperfusion injury in mice and cardiomyocytes [139]. These results raise the concern that CoQ may interfere with the anti-ischemic benefit of statins mediated through stimulation of mitophagy. Therefore, patients treated with statins should be also monitored for their CoQ10 status and clinicians should be aware of the aforementioned interaction between statins and CoQ10 as well as the ability of statins to impair skeletal muscle and myocardial bioenergetics [138].

4.2.3. Flavonoids. Flavonoids are a large family of natural polyphenolic compounds in the human diet and their beneficial effect on cardiovascular diseases is widely studied. These compounds favorably affect a wide range of biological processes. Beside their antioxidant capacity, flavonoids improve lipid profile and have anti-inflammatory, antiplatelet, and antithrombotic effects as well.

Green Tea Catechins (GTC). Catechins are abundant polyphenols in green tea. GTC were shown to reduce blood cholesterol level in both animals [140-143] and humans [144147]. In addition, GTC reduced accumulation of cholesterol in the rat myocardium in a state of diabetic dyslipidemia [141]. In a double-blind, placebo-controlled clinical study, obese, hypertensive patients had decreased LDL-cholesterol and increased HDL and total serum antioxidant levels after 3 months of GTC supplementation [148]. Mehra et al. demonstrated that catechin hydrate improved high sucrose, high-fatinduced cardiac lipid peroxidation and activity of antioxidant enzymes [149]. GTC were reported to beneficially affect highfructose diet-associated hypercholesterolemia and cardiac signaling pathways related to lipid metabolism and inflammation [150]. Age-related cardiac oxidative stress was also improved by GTC [151]. The effect of GTC on hypercholesterolemia associated with cardiac dysfunction is not known, but it was reported that GTC ameliorates myocardial function after ischemia $[152,153]$ in pressure-induced chronic heart failure [154] and in autoimmune myocarditis as well [155]. 
Troxerutin. Troxerutin can be isolated from the Japanese pagoda tree (Sophora japonica). To the best of our knowledge, the antioxidant effect of troxerutin on the heart was first described in an ischemia/reperfusion model [156]. Geetha et al. have investigated the cardiac impact of troxerutin in high-fat high-fructose mice model. They have found that troxerutin reduces cholesterol content and oxidative stress markers in both the plasma and the heart and increases cardiac enzymatic and nonenzymatic antioxidant levels [157]. Moreover, the same group have shown in the same dyslipidemic model that troxerutin reverses fibrotic changes in the heart and improves cardiac function probably by reducing ROS production [158].

Quercetin. The cardioprotective effect of the dietary flavonoid quercetin (found in many fruits, vegetables, leaves, and grains) against ischemia/reperfusion injury is well studied [159-163]; however, few studies are available in the literature regarding the impact on hypercholesterolemia-induced oxidative stress in the heart. It was reported that quercetin ameliorates left ventricular function, collagen deposition, and inflammatory cell infiltration in rats with metabolic syndrome [164]. In that study, quercetin increased the expression of the transcription factor Nrf2 and the enzyme heme oxygenase as protective proteins against oxidative stress. Interestingly, quercetin exerted a cardioprotective effect without reducing plasma cholesterol level thereby suggesting a direct cardiac effect. In other studies, quercetin has been shown to reduce serum LDL and increase HDL cholesterol level in hypercholesterolemic rats [165] and lower total cholesterol in rabbits fed a high-cholesterol [166] and high-fat [167] diet. Ulasova et al. showed that quercetin improves lipid profile of ApoE knockout mice and prevents ventricular hypertrophy without affecting myocardial function [168]. In a cadmium-induced toxicity study, quercetin was found to reduce cardiotoxicity and dyslipidemia by attenuating cardiac oxidative stress and lipid parameters [169].

Rutin. Rutin (the glycoside between the quercetin and the disaccharide rutinose) improves cholesterol level in different hypercholesterolemic $[170,171]$ and dyslipidemic $[172,173]$ rodent models. Panchal et al. have shown that rutin supplementation ameliorates blood cholesterol level, cardiac structure, function, inflammation, and oxidative stress related to high carbohydrate high-fat-induced dyslipidemia [173]. In a streptozotocin-induced diabetes model associated with hyperlipidemia, rutin attenuated serum cholesterol level and myocardial necrosis and improved left ventricular dysfunction [174]. It was also reported that rutin exerts cardioprotection by attenuating oxidative stress and dyslipidemia induced by high fluoride administration in rats [172].

Silymarin. Silymarin is a mixture of three flavonolignans (silibinin, silydianin, and silychristin) extracted from milk thistle seeds (Silybum marianum). Krečman et al. demonstrated that silymarin prevented the development of hypercholesterolemia in high-cholesterol-fed rats [175]. They have also shown that silibinin itself was not as effective as silymarin. Others also reported that silymarin or its fraction decreased total and LDL cholesterol and attenuated oxidative stress in the plasma [176-178]. The effect of silymarin on hypercholesterolemia-induced myocardial oxidative stress is not yet investigated, but some studies indicate that silymarin exerts cardioprotection against high-cholesterolmediated oxidative stress. Silymarin attenuates myocardial ischemia/reperfusion injury by modulating oxidative stress [179] and silibinin has a direct antioxidant effect on H9c2 cardiac cells against oxidative stress [180]. Moreover, silibinin was reported to improve both plasma and cardiac cholesterol content and attenuate oxidative markers and degenerative changes in the heart of animals exposed to arsenic [181]. In this study, silibinin prevented cardiac oxidative stress by inhibiting the induction of prooxidants (e.g., NOX2 and NOX4) and enhancing antioxidants.

Naringin and Hesperidin. Naringin and hesperidin are natural flavonglycosides in citrus fruits. Many studies reported hypocholesterolemic effect of naringin and hesperidin in animal models [182-188] and in a clinical study [189]. However, in moderately hypercholesterolemic subjects, naringin and hesperidin failed to lower serum cholesterol [190]. Alam et al. have published that naringin improves ventricular diastolic dysfunction, cardiac inflammatory cell infiltration, and plasma cholesterol in high carbohydrate, high-fat-fed rats [182]. Recently, naringin has been shown to protect against hypercholesterolemia-induced oxidative stress in the heart [191]. The study has demonstrated that naringin ameliorates cardiac lipid accumulation and cardiac oxidative stress markers by enhancing enzymatic and nonenzymatic antioxidants. Moreover, tissue and serum markers of cholesterolinduced cardiac damage were also attenuated by naringin supplementation [191]. Although hesperidin was reported to protect against cardiac injury induced by doxorubicin [192] or ischemia [193, 194], its role in cholesterol-induced cardiac oxidative stress is not known.

4.2.4. Resveratrol. Pleiotropic beneficial effects of the polyphenol resveratrol (food sources include the skin of grapes, blueberries, raspberries, and mulberries) have been extensively studied and many publications indicate its protective function on cholesterol-induced cardiac oxidative stress. A direct antioxidant effect of resveratrol was demonstrated on H9c2 cardiac cells [195]. Louis et al. have demonstrated that resveratrol ameliorates cardiac relaxation dysfunction in high-fat-fed rats with hypercholesterolemia [196]. They have also shown reduced oxidative stress and inflammatory markers in the serum as a result of resveratrol treatment [196]. In hypercholesterolemic rats with normal cardiac function, resveratrol improved postischemic recovery of the heart [197]. Large animal studies from the same research group reported that resveratrol improved high-cholesterol and chronic ischemia-induced cardiac dysfunction and oxidative damage of myocardial proteins [198-200]. The group also described that resveratrol improved high-cholesterolinduced myocardial dysfunction without decreasing protein oxidation in the absence of ischemia [198]. Chu et al. have shown that red wine ameliorates cardiac dysfunction and 
oxidative stress in hypercholesterolemic swine subjected to chronic ischemia [50]. Resveratrol was reported to improve lipid profile and cardiac dysfunction related to hyperlipidemia in streptozotocin-induced diabetes [201]. Finally, these results may promote new studies focusing on cholesterol-induced cardiac oxidative stress.

4.2.5. Grape Seed. Grape seed and skin are rich in natural antioxidants, so these are possible supplements to alleviate hypercholesterolemia-induced oxidative stress. In a highfat-induced obesity model, grape seed extract was shown to improve lipid profile and prevent postischemic heart dysfunction and cardiac lipid accumulation along with attenuated oxidative stress [202, 203]. Lee et al. reported that grape skin ameliorates total serum antioxidant capacity of rats with high-fat diet and low-fat diet [204]. Antioxidant effect of grape seed was tested on cardiomyoblast H9c2 cell culture [205], where it increased endogenous antioxidant systems and prevented ROS-induced apoptosis [205]. In vivo pretreatment with grape seed proanthocyanidins improved postischemic functional recovery and reduced ROS production in normocholesterolemic rats [206] and partially restored the harmful cardiac effects of hypercholesterolemia via their ability to reduce ROS in the myocardium [207].

4.2.6. Sour Cherry Seed Extract. Based on the observation that cherries contain bioactive phytochemicals, for example, phenolics and anthocyanins, which are reported to possess antioxidant, anti-inflammatory, anticancer, antidiabetic, and antiobesity properties, Tosaki and his group hypothesized that the seed kernel of sour cherry (Prunus cerasus) may contain different bioactive constituents [208]. They demonstrated that kernel extract obtained from sour cherry seed improves postischemic cardiac functional recovery and the incidence of ventricular fibrillation and tachycardia in isolated working rat hearts [209]. Moreover, sour cherry seed extract-induced improvement in cardiac function after ischemia/reperfusion along with decreased atherosclerotic plaque formation and infarct size was also observed in hypercholesterolemic New Zealand rabbits fed a $2 \%$ cholesterolenriched diet for 16 weeks [210]. In this model, the authors demonstrated an increased HO-1 and cytochrome c oxidase III protein expression following administration of sour cherry seed extract as a possible mechanism of action [210, 211].

4.2.7. Spices. Aqueous extracts of certain spices including garlic (Allium sativum), ginger (Zingiber officinale), and cayenne pepper (Capsicum frutescens) as well as their mixture were shown to attenuate cardiac lipid peroxidation induced by high-cholesterol, high-fat diet in a rat model of hypercholesterolemia [20]. Moreover, in the same study, hypercholesterolemia-induced decrease in the myocardial activities of antioxidant enzymes (i.e., SOD, glutathione peroxidase, and glutathione reductase) was also markedly attenuated by administration of the individual spices as well as their combination [20].
4.2.8. Red Palm Oil. Red palm oil (RPO) is a product from the fruits of the oil palm tree (Elaeis guineensis). RPO depending on the producer consists of about $51 \%$ saturated fatty acids (SFAs), 38\% monounsaturated fatty acids (MUFAs), $11 \%$ polyunsaturated fatty acids (PUFAs), and a spectrum of antioxidative carotenoids with tocopherols and tocotrienols as the major constituents [212]. Other minor components present in this oil are ubiquinones (mainly CoQ10) and phytosterols. Red palm oil is therefore a natural carotenoid rich oil that has the potential to act as a very potent antioxidant [213]. Red palm oil contains the highest concentration of tocotrienols compared with other vegetables or plants and Serbinova et al. showed that tocotrienols can be 40-60 times more potent as antioxidants than tocopherols [214].

Van Rooyen's research group investigated the effect of dietary administration of RPO on the heart. They showed that prolonged dietary feeding with RPO-supplemented diet $(\sim 7 \mathrm{~g} \mathrm{RPO} / \mathrm{kg}$ diet$)$ protected the heart against ischemia/reperfusion injury in rats. They used isolated heart models, perfused both in Langendorff technique [215-218] and working mode $[212,219]$, showing the vascular-independent direct cardioprotective effects of RPO. RPO administration improved cardiac function during reperfusion [212] and decreased infarct size $[215,216]$. The real advantage of RPO administration became apparent when RPO was given to hyperlipidemic rats. Hyperlipidemia was induced by feeding animals with $2 \%$ cholesterol-enriched diet for 5-9 weeks. This model was characterized by mild cholesterol elevation but a marked decrease of cardiac performance. RPO was able to markedly increase aortic output recovery after $25 \mathrm{~min}$ global ischemia [219, 220], or infarct size [215] after $30 \mathrm{~min}$ global ischemia, showing the protective effect of RPO in the presence of comorbidities.

The proposed mechanism by which RPO exerts its cardioprotective effect in animals fed high-cholesterol diet is not fully understood. Supplementation with RPO in the presence of potentially harmful cholesterol showed no significant difference in serum cholesterol level; therefore, its protection cannot be explained by the cholesterol-lowering effect of RPO. It is proposed that the protective effect of RPO in high-cholesterol diet may be associated with either the RPO antioxidant characteristics and/or changes in the fatty acid composition of the myocardium during ischemia/reperfusion.

\subsection{Promising Novel Approaches to Modulate Hypercholesterolemia-Induced Oxidative Stress}

4.3.1. miR Modulation. Only $3 \%$ of the human genome codes for proteins and the remaining part consist of noncoding RNAs including short microRNAs (miRNAs, miRs; approximately 18-25 nucleotides in length) [221, 222]. miRNAs can inhibit the translation or promote mRNA degradation by binding to specific mRNAs according to the complementarity of their seed sequences [223]. Individual miRNAs may simultaneously target multiple mRNAs. However, the expression of individual mRNAs can be regulated by multiple miRNAs. Therefore, miRNAs may act as fine tuners or as on/off switchers of gene expression $[223,224]$. Dysregulation of miRNAs 
TABLE 1: Regulation of miRNAs in hyperlipidemia.

\begin{tabular}{|c|c|c|c|c|c|c|}
\hline miRNA & $\begin{array}{c}\text { Regulation of } \\
\text { miRNA }\end{array}$ & Organ & Target & $\begin{array}{c}\text { Regulation of } \\
\text { target }\end{array}$ & Role & References \\
\hline let-7g & down & Aorta & ox-LDL receptor 1 & up & ox-LDL cholesterol uptake & {$[24]$} \\
\hline miR-25 & down & Heart & NOX4 & up & Oxidative stress & {$[8]$} \\
\hline miR-33 & up & $\begin{array}{c}\text { Liver, } \\
\text { macrophages }\end{array}$ & $\mathrm{ABCA} 1$ & down & $\begin{array}{l}\text { Reverse cholesterol } \\
\text { transport }\end{array}$ & {$[25]$} \\
\hline miR-33 & up & $\begin{array}{c}\text { Peripheral } \\
\text { tissues }\end{array}$ & ABCG1 & down & $\begin{array}{l}\text { Reverse cholesterol } \\
\text { transport }\end{array}$ & {$[25,26]$} \\
\hline miR-33 & down & Liver & $\begin{array}{l}\text { Fatty acid } \\
\text { synthesis }\end{array}$ & down & VLDL synthesis & {$[27]$} \\
\hline miR-33 & down & Liver & $\begin{array}{l}\text { Fatty acid } \\
\text { oxidation }\end{array}$ & up & VLDL synthesis & {$[27]$} \\
\hline miR-144 & up & Liver & ABCA1 & down & $\begin{array}{l}\text { Reverse cholesterol } \\
\text { transport }\end{array}$ & {$[28]$} \\
\hline miR-223 & up & Liver & $\begin{array}{c}\text { HMG-CoA } \\
\text { synthase } 1\end{array}$ & down & Cholesterol biosynthesis & [29] \\
\hline miR-223 & up & Liver & $\begin{array}{l}\text { Scavenger } \\
\text { receptor B1 }\end{array}$ & down & HDL cholesterol uptake & [29] \\
\hline miR-208a & up & Heart & MED13 & down & Glucose tolerance & [30] \\
\hline $\begin{array}{l}\text { miR-378 and } \\
\text { miR-378 }\end{array}$ & up & Liver & MED13 & down & Glucose tolerance & {$[31]$} \\
\hline $\begin{array}{l}\operatorname{miR}-378 \text { and } \\
\text { miR-378* }\end{array}$ & up & $\begin{array}{l}\text { Insulin } \\
\text { dependent } \\
\text { tissues }\end{array}$ & $\begin{array}{l}\text { Fatty acid } \\
\text { oxidation }\end{array}$ & down & Obesity & {$[31]$} \\
\hline
\end{tabular}

ABC: ATP-binding cassette transporter; HDL: high density lipoprotein; VLDL: very low density lipoprotein; MED: mediator complex subunit; NOX: NADPH oxidase.

in pathological conditions may alter gene networks; therefore miRNA replacement or antisense inhibition therapy offers a new approach to treating diseases by modulating gene pathways rather than single molecular targets [222].

In recent years, a growing body of evidence has demonstrated that miRNAs play a role in the development of numerous cardiovascular diseases. Several excellent reviews focus on miRNAs as diagnostic markers and potential therapeutic targets in cardiac pathologies including acute coronary syndrome $[221,225]$ and remodelling after myocardial infarction as well as heart failure [25, 221, 224, 226-228] and their risk factors including hypercholesterolemia [229], diabetes mellitus [230, 231], arterial hypertension [232, 233], atherosclerosis [234, 235], and aging [227].

Hypercholesterolemia is a well-known risk factor of cardiovascular diseases and it leads to increased oxidative/nitrative stress in the myocardium. Experimental data are very limited on the regulatory role of miRNAs in hypercholesterolemia-induced oxidative/nitrative stress in cardiac pathologies. We have previously shown that the myocardial downregulation of miR-25 results in the upregulation of NADPH oxidase 4 (NOX4) mediating oxidative/nitrative stress and subsequent myocardial dysfunction in male hypercholesterolemic rats [8] (Table 1). Moreover, in a recent study, decreased circulating miRNA-25 level has been related to the level of oxidative stress indicators in septic patients and the clinical accuracy of miRNA-25 for sepsis diagnosis has been reported to be better than C-reactive protein [236]. In addition, downregulation of miR-25 expression has been demonstrated in cardiac hypertrophy induced by transverse aortic constriction surgery in mice; however, there is no data published on increased oxidative/nitrative stress or cholesterol levels in that study [237]. Furthermore, in vivo inhibition of miR-25 by a specific antagomir resulted in the spontaneous development of cardiac dysfunction and sensitized the myocardium to develop heart failure in a Hand2dependent manner [237]. In contrast, inhibition of overexpressed miR-25 was reported to ameliorate contractile dysfunction by improving sarco/endoplasmic reticulum $\mathrm{Ca}^{2+}$ ATPase (SERCA)2a activity and $\mathrm{Ca}^{2+}$ handling in chronic heart failure induced by transverse aortic constriction surgery in mice as well as in failing human heart samples; however, data on the presence of hypercholesterolemia in humans were lacking in this study [238].

It is well known that hyperlipidemia, obesity, metabolic syndrome, and heart failure are associated with abnormal cardiac metabolism. In obese mice, a heart specific miRNA, miR-208a, has been reported to negatively regulate mediator complex subunit 13 (MED13), which controls transcription by thyroid hormone and other nuclear hormone receptors [30] (Table 1). Indeed, cardiac-specific overexpression of MED13 or pharmacologic inhibition of miR-208a in mice has been demonstrated to confer resistance to high-fat dietinduced obesity and improve systemic glucose tolerance [30] (Table 1). Moreover, mice genetically lacking miR-378 and $\mathrm{miR}-378^{*}$ have been shown to be resistant to high-fat diet-induced obesity and exhibit enhanced mitochondrial fatty acid metabolism and elevated oxidative capacity of 
insulin-target tissues [31] (Table 1). Interestingly, MED13 and carnitine $\mathrm{O}$-acetyltransferase, a mitochondrial enzyme involved in fatty acid metabolism, are among the many targets of miR-378 and miR-378* [31] (Table 1). Thus, these miRNAs provide potential therapeutic targets in hyperlipidemia and metabolic disorders, although their myocardial function needs to be further investigated.

High level of LDL cholesterol and low level of HDL cholesterol are both well known as independent risk factors of coronary artery diseases. miRNAs have been shown to regulate lipoprotein metabolism and their pro-/antiatherogenic effects at many levels in different tissues as reviewed by others $[25,222,229]$. Cholesterol efflux from cells is the first step in reverse cholesterol transport to the liver carried out by HDL. miR-33 has been reported to modulate cholesterol efflux by repressing the expression of ATP-binding cassette transporter $(\mathrm{ABC}) \mathrm{Al}$ in the liver and $\mathrm{ABCA1}$ as well as ABCG1 in peripheral tissues [25] (Table 1). Moreover, antimiR-33 therapy was shown to induce the expression of ABCA1 in macrophages in atherosclerotic plaques thereby reducing the plaque size and local inflammation in mice [26] (Table 1). In addition, anti-miR-33 therapy in nonhuman primates increased the expression of miR-33 target genes involved in fatty acid oxidation and reduced the expression of genes associated with fatty acid synthesis in the liver resulting in a marked suppression of plasma VLDL triglyceride levels [27] (Table 1). Another miRNA, miR-144, has been reported to decrease hepatic ABCA1 expression and plasma HDL cholesterol levels [28] (Table 1). Moreover, miR-223 has been demonstrated to reduce HDL cholesterol uptake by decreasing the expression of scavenger receptor $\mathrm{B} 1$ and to decrease cholesterol biosynthesis through the direct repression of HMG-CoA synthase 1 in the liver of $\mathrm{ApoE}^{-/-}$mice [29] (Table 1). Furthermore, genetic ablation of miR-223 resulted in elevated hepatic and plasma total cholesterol levels as well as increased HDL cholesterol levels and particle size [29] (Table 1). Interestingly, aortae of mice fed with high-fat diet for 6 weeks and human hypercholesterolemic sera showed decreased let-7g expression [24] (Table 1). In the same study a negative feedback regulation has been identified between oxidized LDL receptor 1 and let- $7 \mathrm{~g}$ in primary human aortic smooth muscle cells [24] (Table 1).

Certain microRNAs have been implicated in cellular responses to oxidative/nitrative stress in cardiovascular pathologies in preclinical studies [33, 238-241]. Many miRNAs, including miR-21 and miR-199a, have been reported to play a role in cardiomyocyte survival during ischemia [33, 242] (Table 1). Moreover, injection of AAV9 vectors expressing miR-199 and 590 into the peri-infarcted area of the myocardium could reduce infarct size and improve regeneration after myocardial infarction in mice [243]. We and others have shown that several miRNAs including miR-1, miR-21, miR-125b*, miR-139-3p, miR-139-5p, miR-181a, miR188, miR-192, miR-212, miR-320, miR-487b, and miR-532 play a role in the mechanism of ischemic preconditioning conferring cardioprotection after ischemia/reperfusion injury $[32,34]$ (Table 2). These miRNAs also drive the synthesis of important cardioprotective proteins including heat shock
TABLE 2: miRNAs affected by ischemic pre- or postconditioning in the heart.

\begin{tabular}{|c|c|c|c|}
\hline miRNA & $\begin{array}{c}\text { I/R versus } \\
\text { control }\end{array}$ & Ipre versus I/R & $\begin{array}{c}\text { Ipost versus } \\
I / R\end{array}$ \\
\hline let-7b & down [32] & n.a. [32] & up [32] \\
\hline miR-21 & down [33] & up $[34,35]$ & $\begin{array}{c}\text { n.a. [35] } \\
\text { up [36] }\end{array}$ \\
\hline miR-125b* & down [32] & up [32] & up [32] \\
\hline miR-139-3p & down [32] & up [32] & up [32] \\
\hline miR-181a & down [32] & down [32] & up [32] \\
\hline miR-199a & down [33] & up [34] & no data \\
\hline miR-328 & down [32] & n.a. [32] & up [32] \\
\hline miR-335 & down [32] & n.a. [32] & up [32] \\
\hline miR-503 & down [32] & n.a. [32] & up [32] \\
\hline let-7e & n.a. [32] & n.a. [32] & up [32] \\
\hline let-7i & n.a. [32] & n.a. [32] & up [32] \\
\hline miR-1 & $\begin{array}{c}\text { n.a. }[32], \\
\text { down }[37,38]\end{array}$ & up [34] & $\begin{array}{l}\text { up }[32,37] \text {, } \\
\text { down }[35]\end{array}$ \\
\hline miR-139-5p & n.a. [32] & up [32] & n.a. [32] \\
\hline miR-188 & n.a. [32] & up [32] & up [32] \\
\hline miR-192 & n.a. [32] & up [32] & n.a. [32] \\
\hline miR-212 & n.a. [32] & up [32] & n.a. [32] \\
\hline miR-532 & n.a. [32] & up [32] & up [32] \\
\hline miR-133a & $\begin{array}{l}\text { up [34], } \\
\text { down [37] }\end{array}$ & no data & up [37] \\
\hline miR-208a & up $[32,34]$ & n.a. [32] & down [32] \\
\hline miR-320 & $\begin{array}{l}\text { up [34], } \\
\text { down [32] }\end{array}$ & down [32] & down [32] \\
\hline $\mathrm{miR}-487 \mathrm{~b}$ & up [32] & down [32] & n.a. [32] \\
\hline
\end{tabular}

I/R: ischemia/reperfusion; Ipre: ischemic preconditioning; Ipost: ischemic postconditioning; n.a.: not affected.

protein- (HSP-) 70, endothelial and inducible NOS, HSP-20, NAD-dependent deacetylase sirtuin-1 (Sirt1), and hypoxiainducible factor 1a [34]. miRNAs are also associated with the protective effect of ischemic postconditioning against myocardial ischemia/reperfusion injury. Heart specific miR1 and miR-133a have been associated with playing a role in the cardioprotection conferred by ischemic postconditioning through the regulation of apoptosis-related genes $[35,37]$; however, the regulation of miR-1 by ischemic postconditioning is controversial $[32,35,37]$ (Table 2). Another miRNA, miR-21, has been demonstrated to be implicated in ischemic postconditioning, though its role in cardioprotection is controversial $[35,36]$ (Table 2). In addition, loss of the miR-144/451 cluster function has been shown to limit the cardioprotective effect of ischemic preconditioning by upregulating Rac-1-mediated oxidative stress signaling [38]. Therefore, further preclinical and clinical studies are needed to investigate the role of miRNAs in ischemia/reperfusion injury and myocardial stress adaptation in healthy and diseased conditions, including hypercholesterolemia.

miRNAs exert control over diverse metabolic pathways and are frequently dysregulated in cardiovascular diseases. 
Thus, miRNAs have become a class of promising therapeutic targets. Until miRNA-based therapeutic interventions become a reality in clinical medicine many questions should be answered in preclinical and clinical studies [244]. Better technologies and more applicable in vitro and in vivo models of human diseases should be developed to identify and validate direct mRNA targets of miRNAs [244]. Furthermore, improved understanding of the mechanism of action in each tissue type is necessary. Moreover, development of organ specific delivery methods for miRNA mimics and anti-miR oligonucleotides are needed [244]. Nevertheless, assessment of the efficacy and safety including the analysis of the off-target effects of miRNA-based therapeutic tools and understanding of the long-term effects of miRNA modulation in vivo are of key importance in the future [244].

4.3.2. Peroxynitrite Scavenging. Peroxynitrite is formed by the rapid reaction of superoxide and $\mathrm{NO}$ and is responsible for a variety of deleterious effects in cardiovascular pathologies [245]. Therefore, development of peroxynitrite scavengers or compounds catalyzing the decomposition of peroxynitrite to nontoxic products has been an emerging field in the last decade [245]. Formation of peroxynitrite in the heart of hypercholesterolemic animals has been demonstrated in various experimental models $[6,8,246]$. The beneficial effect of decomposition of cardiac peroxynitrite leading to improved cardiac function in experimental hypercholesterolemia was also shown $[6,246]$. In isolated working hearts from Wistar rats or apoB100 transgenic mice fed with cholesterol-enriched diet, deterioration of cardiac function characterized by increased left ventricular end-diastolic pressure (LVEDP) or decreased aortic flow was demonstrated, respectively $[6,246]$. Pretreatment of the animals with the peroxynitrite decomposition catalyst FeTPPS (5,10,15,20-tetrakis(4-sulfonatophenyl)porphyrinato iron (III), chloride) before isolation of the hearts resulted in an improved LVEDP and aortic flow, respectively [6, 246]. Whether application of peroxynitrite scavengers would reverse impaired conditioning in hypercholesterolemic animals remains to be addressed in future studies.

4.3.3. Hydrogen. Recent advances in basic and clinical research have indicated that hydrogen gas is an important physiological regulatory factor with antioxidant, antiinflammatory, and antiapoptotic protective effects, and thus the application of molecular hydrogen as a therapeutic medical gas in diverse disease conditions has become a feasible therapeutic strategy [247]. Hydrogen is suggested to be an efficient, nontoxic, highly bioavailable, and low-cost antioxidant supplement for patients with pathological conditions involving ROS-induced oxidative stress [248]. Therapeutic hydrogen can be applied by different delivery methods including inhalation of hydrogen gas, drinking hydrogen dissolved in water, and injection with hydrogen-saturated saline [247]. In the heart, hydrogen attenuated doxorubicininduced heart failure in rats [249], cardiac dysfunction in streptozotocin-induced diabetic mice [250], rat cardiac cold ischemia/reperfusion injury [251], and left ventricular hypertrophy in spontaneous hypertensive rats [252] and exerted cardioprotective effects on isoproterenol-induced myocardial infarction in rats [253]. Moreover, inhalation of hydrogen attenuated increased serum cholesterol, cardiac superoxide production, and left ventricular remodeling induced by intermittent hypoxia in mice [254]. Similarly, consumption of hydrogen-rich water beneficially affected serum cholesterol status and oxidative stress markers in patients with potential metabolic syndrome or isolated hypercholesterolemia [255, 256]. These promising results should be confirmed.

4.3.4. Miscellaneous Examples. Diphenyl diselenide has been recently reported to attenuate hypercholesterolemia-associated cardiac oxidative stress and increase antioxidants without affecting plasma level of cholesterol in LDL receptor knockout mice [257].

Local infiltration of neuropeptide $\mathrm{Y}$ to hypercholesterolemic swine heart subjected to ischemia was shown to ameliorate cardiac diastolic dysfunction probably by decreasing oxidative stress and fibrosis and increasing cell survival in the heart $[258,259]$.

4.4. Physical Activity. A dramatic decrease in an individual's physical activity is the most obvious change accompanied by western-type lifestyle and technical development in the industrial countries. Physical inactivity is a risk factor and promotes development of civilization diseases. It is widely accepted that physical activity positively influences a variety of clinical diseases including obesity, metabolic syndrome, dys- and hyperlipidemias, diabetes, and cardiovascular diseases [260, 261].

Hypercholesterolemia is accepted as one of the most important risk factors in the development of different vascular and heart diseases. Physical activity and change in lifestyle are the first choices in normalization of patient's high blood cholesterol level. The mechanisms by which physical activity prevents development of metabolic diseases are rather diverse. The primary effect of physical activity can be seen in a metabolic level. Due to higher energy demand, physical activity intensively increases weight loss. A weight loss of 10 percent can significantly lower the risk of cardiovascular diseases by reversing hyperlipidemia. Moreover, by increasing the catabolic rate of the body, physical exercise positively influences carbohydrate and lipid metabolism and blood lipid profile. Thus, exercise training is associated with increased reliance on lipids as an energy substrate, has a systemic lipid-lowering effect, and results in remodeling of skeletal muscle lipid metabolism toward increased oxidation and neutral lipid storage and turnover [262]. Physical activity has substantial effects on the liver metabolism as well, modifying lipoprotein levels to a more healthy composition. These effects can be enhanced by using concurrent dietary restrictions; for example, a lowcholesterol diet definitely helps to regulate lipid profile in the body. Regular participation in physical activity as well as a single exercise session can positively alter cholesterol metabolism [263]. Exercise is involved in increasing the production and action of several enzymes that function to enhance the reverse cholesterol transport system [263]. 
Nevertheless, physical activity has secondary effects on the prevention of development of metabolic diseases by, for example, modifying oxidative stress. Physical activity is believed to be a protective modulator of oxidative stress in hyperlipidemia; however, high intensity physical exercise itself can definitely increase oxidative stress in patients [264266]. Two key free radicals are the most important during physical activity, that is, superoxide and NO. The exact sources of these radicals are not fully known; however, mitochondria are often cited as the predominant source of ROS in muscle cells. Investigators have often assumed that the increased ROS generation that occurs in muscle fibers during contractile activity is directly related to the elevated oxygen consumption. However, growing evidence argues against mitochondria being the dominant source of ROS production in skeletal muscle during exercise [264]. Another possible source is NADPH oxidase, which is normally quiescent, but when it becomes activated, during muscle contraction or when recruited for antimicrobial and proinflammatory events, it can generate large amounts of superoxide [264, 267, 268]. Since the discovery that contracting skeletal muscles produce ROS, many investigators have assumed that skeletal muscle provides the major source of free radical and ROS generation during exercise. Nonetheless, other tissues such as the heart, lungs, or blood may also contribute to the total body generation of ROS during exercise [264]. Thus the increased catabolic process together with multiplied oxygen consumption in both skeletal and cardiac muscles during exercise exacerbates superoxide production.

The other major free radical which contributes to oxidative/nitrative stress is NO. NO is responsible for the relaxation of vessels [269] and plays an important role in matching tissue perfusion to demand [270]. The release of nitric oxide by the endothelial cell can be upregulated by exercise $[261,271]$. However, hypercholesterolemia impairs endothelial function (e.g., the NO-cyclic GMP-phosphodiesterase 5 pathway), limits shear stress-induced vasodilation, and is therefore expected to reduce exercise-induced vasodilation [272].

In addition to the modulation of ROS and RNS production, physical exercise may also affect the antioxidant defense systems. McCommis et al. have demonstrated that familial hypercholesterolemia reduces mitochondrial antioxidants, increases mitochondrial oxidative stress, and enhances the mitochondrial permeability transition response in the porcine myocardium [19]. They also showed that exercise training can reverse these detrimental alterations without altering serum cholesterol level [19].

In spite of the extensive research, the cardioprotective effect of exercise which is mediated by redox changes is still a question of debate. Several studies showed that hyperlipidemia impairs exercise capacity itself [273] or the effect of physical activity [272, 274, 275]. However, a number of exercise programs have effectively reversed hypercholesterolemia-induced changes mainly within the vasculature by improving $\mathrm{NO}$ bioavailability in both animal studies and humans [276-281].

The exact explanation why physical activity, which similarly to hyperlipidemia leads to an increased oxidative stress, is able to protect the heart in hypercholesterolemia is rather difficult. One possible answer is that during exercise an intensive but only a temporary increase of oxidative stress occurs resulting in a possibility for cardiac adaptation by an improved enzymatic and nonenzymatic antioxidant capacity, cytoprotection, aerobic capacity, training-induced muscular adaptation, mitochondrial biogenesis, and so forth [268]. In hypercholesterolemia with no exercise, the continuously elevated oxidative/nitrative stress, however, does not allow the completion of cardioprotective mechanisms. End-effectors of cardioprotection involve the activation of ATP-sensitive $\mathrm{K}^{+}$-channels (KATP). We have recently demonstrated that a cholesterol-enriched diet inhibited cardioprotection induced by KATP activators and that cholesterol diet may impair cardiac KATP channels [282]. It is well accepted that the opening of KATP channels generates ROS; however, an ambient oxidative state also modifies redox-sensitive KATP channels, as superoxide, hydrogen peroxide, and peroxynitrite open KATP channels in the heart. These results show that increased oxidative stress interferes with KATP channel function and therefore might explain why cardioprotection is lost in hyperlipidemia.

Increased physical activity can be also mimicked in experimental animal models by applying ventricular overdrive pacing of the heart, a method that was reported to induce both preconditioning and postconditioning by increasing the oxygen demand (relative hypoxia) instead of limiting oxygen supply (absolute hypoxia) in isolated heart models [283285]. Peroxynitrite plays an important role in different conditionings induced by either ischemia or ventricular pacing $[11,286]$. It is known that experimental hypercholesterolemia blocks the cardioprotective effect of postconditioning at least in part via deterioration of postconditioning-induced early increase in peroxynitrite formation during reperfusion [11]. Thus one can speculate that regular physical exercise is able to restore the protective effects of pre- or postconditioning in hypercholesterolemia via modifying cardiac oxidative stress and by beneficially altering lipid profile in the blood.

In addition to emphasizing the importance of regular exercise, novel future directions have been implicated to take advantage of exercise-induced benefits. Thus development of new "exercise mimetics" has a promising role in the future for treatment of patients [287].

\section{Conclusions}

Oxidative and nitrative stress has been implicated as a pathophysiological mechanism of cardiovascular diseases; however, there is still no breakthrough regarding the use of general antioxidant therapies in clinical practice. The possible reasons for these disappointing results and some promising aspects of potential antioxidant therapy have been discussed in detail recently [288]. Although hypercholesterolemia occurs frequently in the adult population, the number of publications investigating myocardial oxidative/nitrative stress and its cardiac consequences is relatively limited especially in humans. This is unfortunate, as patients with hypercholesterolemia are at an increased risk for severe pathological conditions such as myocardial infarction and heart failure and hypercholesterolemia has been shown 
to interfere with endogenous cardioprotective mechanisms. Therefore, finding proper approaches to beneficially affect hypercholesterolemia and its myocardial consequences is crucial. These reasons warrant further preclinical and clinical studies to better understand the pathological events in the heart relating to hypercholesterolemic conditions and to find the best approaches to interact. Moreover, many of the potential modulators of oxidative/nitrative stress require further development to optimize their effects for application in hypercholesterolemia.

\section{Conflict of Interests}

The authors declare that there is no conflict of interests regarding the publication of this paper.

\section{Acknowledgments}

This work was supported by the European Union, cofinanced by the European Social Fund, within the framework of TÁMOP-4.1.1.C-13/1/KONV-2014-0001 project, and by grants from the Hungarian Scientific Research Fund (OTKA K 115990). Csaba Csonka was supported by the János Bolyai Research Scholarship of the Hungarian Academy of Sciences. The authors thank Jeremy Parrott Ph.D. language editor for proofreading the paper.

\section{References}

[1] E. V. Kuklina, P. W. Yoon, and N. L. Keenan, "Trends in high levels of low-density lipoprotein cholesterol in the United States, 1999-2006," Journal of the American Medical Association, vol. 302, no. 19, pp. 2104-2110, 2009.

[2] V. L. Roger, A. S. Go, D. M. Lloyd-Jones et al., "Executive summary: heart disease and stroke statistics-2012 update: a report from the American Heart Association," Circulation, vol. 125, no. 1, pp. 188-197, 2012.

[3] R. B. Shekelle, A. M. Shryock, O. Paul et al., "Diet, serum cholesterol, and death from coronary heart disease. The Western electric study," The New England Journal of Medicine, vol. 304, no. 2, pp. 65-70, 1981.

[4] K. M. Anderson, W. P. Castelli, and D. Levy, "Cholesterol and mortality. 30 years of follow-up from the Framingham Study," The Journal of the American Medical Association, vol. 257, no. 16, pp. 2176-2180, 1987.

[5] W. J. Rogers, P. D. Frederick, E. Stoehr et al., "Trends in presenting characteristics and hospital mortality among patients with ST elevation and non-ST elevation myocardial infarction in the National Registry of Myocardial Infarction from 1990 to 2006," American Heart Journal, vol. 156, no. 6, pp. 1026-1034, 2008.

[6] T. Csont, E. Bereczki, P. Bencsik et al., "Hypercholesterolemia increases myocardial oxidative and nitrosative stress thereby leading to cardiac dysfunction in apoB-100 transgenic mice," Cardiovascular Research, vol. 76, no. 1, pp. 100-109, 2007.

[7] Y. Huang, K. E. Walker, F. Hanley, J. Narula, S. R. Houser, and T. N. Tulenko, "Cardiac systolic and diastolic dysfunction after a cholesterol-rich diet," Circulation, vol. 109, no. 1, pp. 97-102, 2004.
[8] Z. V. Varga, K. Kupai, G. Szucs et al., "MicroRNA-25dependent up-regulation of NADPH oxidase 4 (NOX4) mediates hypercholesterolemia-induced oxidative/nitrative stress and subsequent dysfunction in the heart," Journal of Molecular and Cellular Cardiology, vol. 62, pp. 111-121, 2013.

[9] R. M. Osipov, C. Bianchi, J. Feng et al., "Effect of hypercholesterolemia on myocardial necrosis and apoptosis in the setting of ischemia-reperfusion," Circulation, vol. 120, no. 1, pp. S22-S30, 2009.

[10] P. Ferdinandy, Z. Szilvássy, L. I. Horváth et al., "Loss of pacinginduced preconditioning in rat hearts: role of nitric oxide and cholesterol-enriched diet," Journal of Molecular and Cellular Cardiology, vol. 29, no. 12, pp. 3321-3333, 1997.

[11] K. Kupai, C. Csonka, V. Fekete et al., "Cholesterol dietinduced hyperlipidemia impairs the cardioprotective effect of postconditioning: role of peroxynitrite," The American Journal of Physiology-Heart and Circulatory Physiology, vol. 297, no. 5, pp. H1729-H1735, 2009.

[12] B. Halliwell, "Biochemistry of oxidative stress," Biochemical Society Transactions, vol. 35, part 5, pp. 1147-1150, 2007.

[13] W. Dröge, "Free radicals in the physiological control of cell function," Physiological Reviews, vol. 82, no. 1, pp. 47-95, 2002.

[14] G. F. Kocsis, T. Csont, Z. Varga-Orvos, L. G. Puskás, Z. Murlasits, and P. Ferdinandy, "Expression of genes related to oxidative/nitrosative stress in mouse hearts: effect of preconditioning and cholesterol diet," Medical Science Monitor, vol. 16, no. 1, pp. BR32-BR39, 2010.

[15] L. G. Puskás, Z. B. Nagy, Z. Giricz et al., "Cholesterol dietinduced hyperlipidemia influences gene expression pattern of rat hearts: a DNA microarray study," FEBS Letters, vol. 562, no. 1-3, pp. 99-104, 2004.

[16] M. Sárközy, Á. Zvara, N. Gyémánt et al., "Metabolic syndrome influences cardiac gene expression pattern at the transcript level in male ZDF rats," Cardiovascular Diabetology, vol. 12, article 16, 2013.

[17] J. J. Repa and D. J. Mangelsdorf, "The role of orphan nuclear receptors in the regulation of cholesterol homeostasis," Annual Review of Cell and Developmental Biology, vol. 16, pp. 459-481, 2000.

[18] A. M. Abbas and H. F. Sakr, "Simvastatin and vitamin e effects on cardiac and hepatic oxidative stress in rats fed on high fat diet," Journal of Physiology and Biochemistry, vol. 69, no. 4, pp. 737-750, 2013.

[19] K. S. McCommis, A. M. McGee, M. H. Laughlin, D. K. Bowles, and C. P. Baines, "Hypercholesterolemia increases mitochondrial oxidative stress and enhances the MPT response in the porcine myocardium: beneficial effects of chronic exercise," American Journal of Physiology-Regulatory, Integrative and Comparative Physiology, vol. 301, no. 5, pp. R1250-R1258, 2011.

[20] G. A. Otunola, O. B. Oloyede, A. T. Oladiji, and A. J. Afolayan, "Selected spices and their combination modulate hypercholesterolemia-induced oxidative stress in experimental rats," Biological Research, vol. 47, no. 1, article 5, 2014.

[21] T. Suanarunsawat, W. D. Na Ayutthaya, T. Songsak, S. Thirawarapan, and S. Poungshompoo, "Lipid-lowering and antioxidative activities of aqueous extracts of Ocimum sanctum L. leaves in rats fed with a high-cholesterol diet," Oxidative Medicine and Cellular Longevity, vol. 2011, Article ID 962025, 9 pages, 2011. 
[22] P. Ferdinandy, C. Csonka, T. Csont, Z. Szilvássy, and L. Dux, "Rapid pacing-induced preconditioning is recaptured by farnesol treatment in hearts of cholesterol fed rats: role of polyprenyl derivatives and nitric oxide," Molecular and Cellular Biochemistry, vol. 186, no. 1-2, pp. 27-34, 1998.

[23] Z. Giricz, C. Csonka, A. Ónody, T. Csont, and P. Ferdinandy, "Role of cholesterol-enriched diet and the mevalonate pathway in cardiac nitric oxide synthesis," Basic Research in Cardiology, vol. 98, no. 5, pp. 304-310, 2003.

[24] K.-C. Chen, I.-C. Hsieh, E. Hsi et al., "Negative feedback regulation between microRNA let-7g and the oxLDL receptor LOX-1," Journal of Cell Science, vol. 124, no. 23, pp. 4115-4124, 2011.

[25] D. Karunakaran and K. J. Rayner, "MicroRNAs in cardiovascular health: from order to disorder," Endocrinology, vol. 154, no. 11, pp. 4000-4009, 2013.

[26] K. J. Rayner, F. J. Sheedy, C. C. Esau et al., "Antagonism of miR-33 in mice promotes reverse cholesterol transport and regression of atherosclerosis," The Journal of Clinical Investigation, vol. 121, no. 7, pp. 2921-2931, 2011.

[27] K. J. Rayner, C. C. Esau, F. N. Hussain et al., "Inhibition of miR$33 \mathrm{a} / \mathrm{b}$ in non-human primates raises plasma HDL and lowers VLDL triglycerides," Nature, vol. 478, no. 7369, pp. 404-407, 2011.

[28] C. M. Ramírez, N. Rotllan, A. V. Vlassov et al., "Control of cholesterol metabolism and plasma high-density lipoprotein levels by microRNA-144," Circulation Research, vol. 112, no. 12, pp. 1592-1601, 2013.

[29] K. C. Vickers, S. R. Landstreet, M. G. Levin et al., "MicroRNA223 coordinates cholesterol homeostasis," Proceedings of the National Academy of Sciences of the United States of America, vol. 111, no. 40, pp. 14518-14523, 2014.

[30] C. E. Grueter, E. van Rooij, B. A. Johnson et al., "A cardiac MicroRNA governs systemic energy homeostasis by regulation of MED13," Cell, vol. 149, no. 3, pp. 671-683, 2012.

[31] M. Carrer, N. Liu, C. E. Grueter et al., "Control of mitochondrial metabolism and systemic energy homeostasis by microRNAs 378 and 378*," Proceedings of the National Academy of Sciences of the United States of America, vol. 109, no. 38, pp. 15330-15335, 2012.

[32] Z. V. Varga, Á. Zvara, N. Faragó et al., "MicroRNAs associated with ischemia-reperfusion injury and cardioprotection by ischemic pre- and postconditioning: protectomiRs," American Journal of Physiology-Heart and Circulatory Physiology, vol. 307, no. 2, pp. H216-H227, 2014.

[33] A. M. Orogo and A. B. Gustafsson, "Cell death in the myocardium: my heart won't go on," IUBMB Life, vol. 65, no. 8, pp. 651-656, 2013.

[34] F. N. Salloum, C. Yin, and R. C. Kukreja, "Role of microRNAs in cardiac preconditioning," Journal of Cardiovascular Pharmacology, vol. 56, no. 6, pp. 581-588, 2010.

[35] X. Duan, B. Ji, X. Wang et al., "Expression of MicroRNA-1 and MicroRNA-21 in different protocols of ischemic conditioning in an isolated rat heart model," Cardiology, vol. 122, no. 1, pp. 3643, 2012.

[36] Y. Tu, L. Wan, Y. Fan et al., "Ischemic postconditioningmediated miRNA-21 protects against cardiac ischemia/reperfusion injury via PTEN/Akt pathway," PLoS ONE, vol. 8, no. 10, Article ID e75872, 2013.
[37] B. He, J. Xiao, A.-J. Ren et al., "Role of miR-1 and miR-133a in myocardial ischemic postconditioning," Journal of Biomedical Science, vol. 18, article 22, 2011.

[38] X. Wang, H. Zhu, X. Zhang et al., "Loss of the miR-144/451 cluster impairs ischaemic preconditioning-mediated cardioprotection by targeting Rac-1," Cardiovascular Research, vol. 94, no. 2, pp. 379-390, 2012.

[39] K. Gaus, E. Gratton, E. P. W. Kable et al., "Visualizing lipid structure and raft domains in living cells with two-photon microscopy," Proceedings of the National Academy of Sciences of the United States of America, vol. 100, no. 26, pp. 15554-15559, 2003.

[40] H. Dalen, A. Thorstensen, P. R. Romundstad, S. A. Aase, A. Stoylen, and L. J. Vatten, "Cardiovascular risk factors and systolic and diastolic cardiac function: a tissue Doppler and speckle tracking echocardiographic study," Journal of the American Society of Echocardiography, vol. 24, no. 3, pp. 322-332.e6, 2011.

[41] T. Horio, J. Miyazato, K. Kamide, S. Takiuchi, and Y. Kawano, "Influence of low high-density lipoprotein cholesterol on left ventricular hypertrophy and diastolic function in essential hypertension," American Journal of Hypertension, vol. 16, no. 11, part 1, pp. 938-944, 2003.

[42] I. Ungi, T. Ungi, Z. Ruzsa et al., "Hypercholesterolemia attenuates the anti-ischemic effect of preconditioning during coronary angioplasty," Chest, vol. 128, no. 3, pp. 1623-1628, 2005.

[43] M. Bountioukos, V. Rizzello, B. J. Krenning et al., "Effect of atorvastatin on myocardial contractile reserve assessed by tissue doppler imaging in moderately hypercholesterolemic patients without heart disease," The American Journal of Cardiology, vol. 92, no. 5, pp. 613-616, 2003.

[44] J. Rubinstein, A. Pelosi, A. Vedre, P. Kotaru, and G. S. Abela, "Hypercholesterolemia and myocardial function evaluated via tissue doppler imaging," Cardiovascular Ultrasound, vol. 7, article 56, 2009.

[45] E. Talini, V. Di Bello, C. Bianchi et al., "Early impairment of left ventricular function in hypercholesterolemia and its reversibility after short term treatment with rosuvastatin. A preliminary echocardiographic study," Atherosclerosis, vol. 197, no. 1, pp. 346-354, 2008.

[46] S.-H. Wan, M. W. Vogel, and H. H. Chen, "Pre-clinical diastolic dysfunction," Journal of the American College of Cardiology, vol. 63, no. 5, pp. 407-416, 2014.

[47] M. M. Redfield, S. J. Jacobsen, J. C. Burnett Jr., D. W. Mahoney, K. R. Bailey, and R. J. Rodeheffer, "Burden of systolic and diastolic ventricular dysfunction in the community: appreciating the scope of the heart failure epidemic," Journal of the American Medical Association, vol. 289, no. 2, pp. 194-202, 2003.

[48] E. M. L. Bastiaanse, D. E. Atsma, M. M. C. Kuijpers, and A. Van der Laarse, "The effect of sarcolemmal cholesterol content on intracellular calcium ion concentration in cultured cardiomyocytes," Archives of Biochemistry and Biophysics, vol. 313, no. 1, pp. 58-63, 1994.

[49] P. Bencsik, V. Sasi, K. Kiss et al., "Serum lipids and cardiac function correlate with nitrotyrosine and MMP activity in coronary artery disease patients," European Journal of Clinical Investigation, vol. 45, no. 7, pp. 692-701, 2015.

[50] L. M. Chu, A. D. Lassaletta, M. P. Robich et al., "Effects of red wine and vodka on collateral-dependent perfusion and cardiovascular function in hypercholesterolemic swine," Circulation, vol. 126, no. 11, supplement 1, pp. S65-S72, 2012. 
[51] M. Canton, S. Menazza, F. L. Sheeran, P. P. de Laureto, F. Di Lisa, and S. Pepe, "Oxidation of myofibrillar proteins in human heart failure," Journal of the American College of Cardiology, vol. 57, no. 3, pp. 300-309, 2011

[52] Z. Hertelendi, A. Tóth, A. Borbély et al., "Oxidation of myofilament protein sulfhydryl groups reduces the contractile force and its $\mathrm{Ca}^{2+}$ sensitivity in human cardiomyocytes," Antioxidants \& Redox Signaling, vol. 10, no. 7, pp. 1175-1184, 2008.

[53] C. E. Murry, R. B. Jennings, and K. A. Reimer, "Preconditioning with ischemia: a delay of lethal cell injury in ischemic myocardium," Circulation, vol. 74, no. 5, pp. 1124-1136, 1986.

[54] Z. Q. Zhao, J. S. Corvera, M. E. Halkos et al., "Inhibition of myocardial injury by ischemic postconditioning during reperfusion: comparison with ischemic preconditioning," The American Journal of Physiology - Heart and Circulatory Physiology, vol. 285, no. 2, pp. H579-H588, 2003.

[55] B. C. G. Gho, R. G. Schoemaker, M. A. Van den Doel, D. J. Duncker, and P. D. Verdouw, "Myocardial protection by brief ischemia in noncardiac tissue," Circulation, vol. 94, no. 9, pp. 2193-2200, 1996.

[56] C. Csonka, Z. Murlasits, P. Ferdinandy et al., "Ischemic stress adaptation of the myocardium in disease states: role of hyperlipidemia," in Advances in Cardiomyocyte Research, PP. Nánási, Ed., pp. 245-265, Transworld Research Network, Kerala, India, 2009.

[57] P. Ferdinandy, R. Schulz, and G. F. Baxter, "Interaction of cardiovascular risk factors with myocardial ischemia/reperfusion injury, preconditioning, and postconditioning," Pharmacological Reviews, vol. 59, no. 4, pp. 418-458, 2007.

[58] K. McCafferty, S. Forbes, C. Thiemermann, and M. M. Yaqoob, "The challenge of translating ischemic conditioning from animal models to humans: the role of comorbidities," Disease Models \& Mechanisms, vol. 7, no. 12, pp. 1321-1333, 2014.

[59] R. N. Schuck, P. M. Mendys, and R. J. Simpson Jr., "Beyond statins: lipid management to reduce cardiovascular risk," Pharmacotherapy, vol. 33, no. 7, pp. 754-764, 2013.

[60] M. H. Frick, O. Elo, K. Haapa et al., "Helsinki Heart study: primary-prevention trial with gemfibrozil in middle-aged men with dyslipidemia. Safety of treatment, changes in risk factors, and incidence of coronary heart disease," The New England Journal of Medicine, vol. 317, no. 20, pp. 1237-1245, 1987.

[61] P. L. Canner, K. G. Berge, N. K. Wenger et al., "Fifteen year mortality in Coronary Drug Project patients: long-term benefit with niacin," Journal of the American College of Cardiology, vol. 8, no. 6, pp. 1245-1255, 1986.

[62] N. J. Stone, J. G. Robinson, A. H. Lichtenstein et al., "2013 ACC/AHA guideline on the treatment of blood cholesterol to reduce atherosclerotic cardiovascular risk in adults: a report of the American college of cardiology/American heart association task force on practice guidelines," Journal of the American College of Cardiology, vol. 63, no. 25, pp. 2889-2934, 2014.

[63] E. Csepanyi, A. Czompa, D. Haines et al., "Cardiovascular effects of low versus high-dose beta-carotene in a rat model," Pharmacological Research, vol. 100, pp. 148-156, 2015.

[64] J. Davignon, "Pleiotropic effects of pitavastatin," British Journal of Clinical Pharmacology, vol. 73, no. 4, pp. 518-535, 2012.

[65] V. G. Athyros, A. I. Kakafika, K. Tziomalos, A. Karagiannis, and D. P. Mikhailidis, "Pleiotropic effects of statins-clinical evidence," Current Pharmaceutical Design, vol. 15, no. 5, pp. 479-489, 2009.

[66] A. O. Abdel-Zaher, A. E. A. Elkoussi, L. H. Abudahab, M. H. Elbakry, and E. A.-E. Elsayed, "Effect of simvastatin on the antihypertensive activity of losartan in hypertensive hypercholesterolemic animals and patients: role of nitric oxide, oxidative stress, and high-sensitivity C-reactive protein," Fundamental of Clinical Pharmacology, vol. 28, no. 3, pp. 237-248, 2014.

[67] E. K. Iliodromitis, I. Andreadou, E. Prokovas et al., "Simvastatin in contrast to postconditioning reduces infarct size in hyperlipidemic rabbits: possible role of oxidative/nitrosative stress attenuation," Basic Research in Cardiology, vol. 105, no. 2, pp. 193-203, 2010.

[68] I. Andreadou, D. Farmakis, E. Prokovas et al., "Short-term statin administration in hypercholesterolaemic rabbits resistant to postconditioning: effects on infarct size, endothelial nitric oxide synthase, and nitro-oxidative stress," Cardiovascular Research, vol. 94, no. 3, pp. 501-509, 2012.

[69] S. Aydin, H. Uzun, V. Sozer, and T. Altug, "Effects of atorvastatin therapy on protein oxidation and oxidative DNA damage in hypercholesterolemic rabbits," Pharmacological Research, vol. 59, no. 4, pp. 242-247, 2009.

[70] R. Cangemi, L. Loffredo, R. Carnevale et al., "Early decrease of oxidative stress by atorvastatin in hypercholesterolaemic patients: effect on circulating vitamin E," European Heart Journal, vol. 29, no. 1, pp. 54-62, 2008.

[71] C. Roberto, P. Pasquale, D. S. Serena et al., "Atorvastatin inhibits oxidative stress via adiponectin-mediated NADPH oxidase down-regulation in hypercholesterolemic patients," Atherosclerosis, vol. 213, no. 1, pp. 225-234, 2010.

[72] A. Nagila, T. Permpongpaiboon, S. Tantrarongroj et al., "Effect of atorvastatin on paraoxonasel (PON1) and oxidative status," Pharmacological Reports, vol. 61, no. 5, pp. 892-898, 2009.

[73] J. R. Murrow, S. Sher, S. Ali et al., "The differential effect of statins on oxidative stress and endothelial function: atorvastatin versus pravastatin," Journal of Clinical Lipidology, vol. 6, no. 1, pp. 42-49, 2012.

[74] N. R. Sodha, M. Boodhwani, B. Ramlawi et al., "Atorvastatin increases myocardial indices of oxidative stress in a porcine model of hypercholesterolemia and chronic ischemia," Journal of Cardiac Surgery, vol. 23, no. 4, pp. 312-320, 2008.

[75] P. M. da Silva, "Are all statins the same?: focus on the efficacy and tolerability of pitavastatin," American Journal of Cardiovascular Drugs, vol. 11, no. 2, pp. 93-107, 2011.

[76] G. Sevin, M. Yasa, D. Y. Akcay, G. Kirkali, and Z. Kerry, "Different responses of fluvastatin to cholesterol-induced oxidative modifications in rabbits: evidence for preventive effect against DNA damage," Cell Biochemistry and Function, vol. 31, no. 4, pp. 325-332, 2013.

[77] M. S. Kostapanos, A. T. Spyrou, C. C. Tellis et al., "Ezetimibe treatment lowers indicators of oxidative stress in hypercholesterolemic subjects with high oxidative stress," Lipids, vol. 46, no. 4, pp. 341-348, 2011.

[78] N. Turfaner, H. Uzun, H. Balci et al., "Ezetimibe therapy and its influence on oxidative stress and fibrinolytic activity," Southern Medical Journal, vol. 103, no. 5, pp. 428-433, 2010.

[79] A. Undas, A. Machnik, D. P. Potaczek, E. Wypasek, K. Zmudka, and W. Tracz, "Ezetimibe combined with simvastatin compared with simvastatin alone results in a greater suppression of 
oxidative stress and enhanced fibrinolysis in patients after acute coronary events," Journal of Cardiovascular Pharmacology, vol. 58, no. 2, pp. 167-172, 2011.

[80] O. Hussein, L. Minasian, Y. Itzkovich, K. Shestatski, L. Solomon, and J. Zidan, "Ezetimibe's effect on platelet aggregation and LDL tendency to peroxidation in hypercholesterolaemia as monotherapy or in addition to simvastatin," British Journal of Clinical Pharmacology, vol. 65, no. 5, pp. 637-645, 2008.

[81] T. Sugizaki, M. Watanabe, Y. Horai et al., “The niemann-Pick C1 like 1 (NPC1L1) inhibitor ezetimibe improves metabolic disease via decreased liver X receptor (LXR) activity in liver of obese male mice," Endocrinology, vol. 155, no. 8, pp. 2810-2819, 2014.

[82] H. Nakagami, M. K. Osako, Y. Takami et al., "Vascular protective effects of ezetimibe in ApoE-deficient mice," Atherosclerosis, vol. 203, no. 1, pp. 51-58, 2009.

[83] J. P. Davies, C. Scott, K. Oishi, A. Liapis, and Y. A. Ioannou, "Inactivation of NPC1L1 causes multiple lipid transport defects and protects against diet-induced hypercholesterolemia," The Journal of Biological Chemistry, vol. 280, no. 13, pp. 12710-12720, 2005.

[84] M. Nomura, H. Ishii, A. Kawakami, and M. Yoshida, "Inhibition of hepatic Niemann-Pick C1-like 1 improves hepatic insulin resistance," American Journal of Physiology -Endocrinology and Metabolism, vol. 297, no. 5, pp. E1030-E1038, 2009.

[85] D. M. Capuzzi, J. M. Morgan, C. M. Carey et al., "Rosuvastatin alone or with extended-release niacin: a new therapeutic option for patients with combined hyperlipidemia," Preventive Cardiology, vol. 7, no. 4, pp. 176-181, 2004.

[86] J. R. Crouse III, "New developments in the use of niacin for treatment of hyperlipidemia: new considerations in the use of an old drug," Coronary Artery Disease, vol. 7, no. 4, pp. 321-326, 1996.

[87] S. Hamoud, M. Kaplan, E. Meilin et al., "Niacin administration significantly reduces oxidative stress in patients with hypercholesterolemia and low levels of high-density lipoprotein cholesterol," The American Journal of the Medical Sciences, vol. 345, no. 3, pp. 195-199, 2013.

[88] P. L. Canner, C. D. Furberg, and M. E. McGovern, "Benefits of niacin in patients with versus without the metabolic syndrome and healed myocardial infarction (from the Coronary Drug Project)," The American Journal of Cardiology, vol. 97, no. 4, pp. 477-479, 2006.

[89] N. A. Trueblood, R. Ramasamy, L. F. Wang, and S. Schaefer, "Niacin protects the isolated heart from ischemia-reperfusion injury," American Journal of Physiology-Heart and Circulatory Physiology, vol. 279, no. 2, pp. H764-H771, 2000.

[90] H. Otani, R. M. Engelman, S. Datta et al., "Enhanced myocardial preservation by nicotinic acid, an antilipolytic compound: improved cardiac performance after hypothermic cardioplegic arrest," The Journal of Thoracic and Cardiovascular Surgery, vol. 96, no. 1, pp. 81-87, 1988.

[91] M. van Bilsen, G. J. van der Vusse, P. H. M. Willemsen, W. A. Coumans, T. H. M. Roemen, and R. S. Reneman, "Effects of nicotinic acid and mepacrine on fatty acid accumulation and myocardial damage during ischemia and reperfusion," Journal of Molecular and Cellular Cardiology, vol. 22, no. 2, pp. 155-163, 1990.
[92] S. T. Tai, Y. H. Fu, Y. C. Yang, and J. Wang, "Niacin ameliorates kidney warm ischemia and reperfusion injury-induced ventricular dysfunction and oxidative stress and disturbance in mitochondrial metabolism in rats," Transplantation Proceedings, vol. 47, no. 4, pp. 1079-1082, 2015.

[93] E. Moutzouri, A. Kei, M. S. Elisaf, and H. J. Milionis, "Management of dyslipidemias with fibrates, alone and in combination with statins: role of delayed-release fenofibric acid," Vascular Health and Risk Management, vol. 6, no. 1, pp. 525-539, 2010.

[94] B. Staels, J. Dallongeville, J. Auwerx, K. Schoonjans, E. Leitersdorf, and J.-C. Fruchart, "Mechanism of action of fibrates on lipid and lipoprotein metabolism," Circulation, vol. 98, no. 19, pp. 2088-2093, 1998.

[95] Y. Dong, B. T. Steffen, J. Cao et al., "Effects of fenofibrate on plasma oxidized LDL and 8-isoprostane in a sub-cohort of GOLDN participants," Atherosclerosis, vol. 214, no. 2, pp. 422425, 2011.

[96] A. E. Walker, R. E. Kaplon, S. M. S. Lucking, M. J. RussellNowlan, R. H. Eckel, and D. R. Seals, "Fenofibrate improves vascular endothelial function by reducing oxidative stress while increasing endothelial nitric oxide synthase in healthy normolipidemic older adults," Hypertension, vol. 60, no. 6, pp. 1517-1523, 2012.

[97] G. S. Sugga, M. U. Khan, and R. Khanam, "Protective role of fibrates in cardiac ischemia/reperfusion," Journal of Advanced Pharmaceutical Technology and Research, vol. 3, no. 3, pp. 188192, 2012.

[98] S. Ichihara, K. Obata, Y. Yamada et al., "Attenuation of cardiac dysfunction by a PPAR- $\alpha$ agonist is associated with downregulation of redox-regulated transcription factors," Journal of Molecular and Cellular Cardiology, vol. 41, no. 2, pp. 318-329, 2006.

[99] A. P. Singh, R. Singh, and P. Krishan, "Ameliorative role of gemfibrozil against partial abdominal aortic constrictioninduced cardiac hypertrophy in rats," Cardiology in the Young, vol. 25, no. 4, pp. 725-730, 2014.

[100] J. Kaur, K. Reddy, and P. Balakumar, "The novel role of fenofibrate in preventing nicotine- and sodium arsenite-induced vascular endothelial dysfunction in the rat," Cardiovascular Toxicology, vol. 10, no. 3, pp. 227-238, 2010.

[101] M. Olukman, E. D. Sezer, S. Ülker, E. Y. Sözmen, and G. M. Çınar, "Fenofibrate treatment enhances antioxidant status and attenuates endothelial dysfunction in streptozotocin-induced diabetic rats," Experimental Diabetes Research, vol. 2010, Article ID 828531, 10 pages, 2010.

[102] A. Guellich, T. Damy, Y. Lecarpentier et al., "Role of oxidative stress in cardiac dysfunction of PPAR $\alpha^{-/-}$mice," American Journal of Physiology-Heart and Circulatory Physiology, vol. 293, no. 1, pp. H93-H102, 2007.

[103] R. K. Vikramadithyan, K. Hirata, H. Yagyu et al., "Peroxisome proliferator-activated receptor agonists modulate heart function in transgenic mice with lipotoxic cardiomyopathy," Journal of Pharmacology and Experimental Therapeutics, vol. 313, no. 2, pp. 586-593, 2005.

[104] J. C. Pettersen, I. Pruimboom-Brees, O. L. Francone et al., "The PPARalpha agonists fenofibrate and CP-778875 cause increased beta-oxidation, leading to oxidative injury in skeletal and cardiac muscle in the rat," Toxicologic Pathology, vol. 40, no. 3, pp. 435-447, 2012. 
[105] L. Ren, Y. Li, Y. Li et al., "The inhibitory effects of rosiglitazone on cardiac hypertrophy through modulating the reninangiotensin system in diet-induced hypercholesterolemic rats," Cell Biochemistry and Function, vol. 28, no. 1, pp. 58-65, 2010.

[106] Z.-H. Wang, F. Luo, and X.-M. Liu, "Effect of PPARgamma agonist rosiglitazone on regression of the atherosclerotic plaques in rabbits," Acta Pharmaceutica Sinica, vol. 40, no. 11, pp. 1051-1053, 2005.

[107] H.-R. Liu, L. Tao, E. Gao et al., "Anti-apoptotic effects of rosiglitazone in hypercholesterolemic rabbits subjected to myocardial ischemia and reperfusion," Cardiovascular Research, vol. 62, no. 1, pp. 135-144, 2004.

[108] H.-R. Liu, L. Tao, E. Gao et al., "Rosiglitazone inhibits hypercholesterolaemia-induced myeloperoxidase upregulation-a novel mechanism for the cardioprotective effects of PPAR agonists," Cardiovascular Research, vol. 81, no. 2, pp. 344-352, 2009.

[109] Y.-J. Kim, K.-J. Park, J.-K. Song et al., “The PPAR $\gamma$ agonist protects cardiomyocytes from oxidative stress and apoptosis via thioredoxin overexpression," Bioscience, Biotechnology and Biochemistry, vol. 76, no. 12, pp. 2181-2187, 2012.

[110] Z. Guo, Z. Qin, R. Zhang, J. Li, and Y. Yin, "Effect of rosiglitazone on the expression of cardiac adiponectin receptors and NADPH oxidase in type 2 diabetic rats," European Journal of Pharmacology, vol. 685, no. 1-3, pp. 116-125, 2012.

[111] D. J. Hausenloy, H. J. Whittington, A. M. Wynne et al., "Dipeptidyl peptidase- 4 inhibitors and GLP-1 reduce myocardial infarct size in a glucose-dependent manner," Cardiovascular Diabetology, vol. 12, article 154, 2013.

[112] M. H. Noyan-Ashraf, E. A. Shikatani, I. Schuiki et al., "A glucagon-like peptide-1 analog reverses the molecular pathology and cardiac dysfunction of a mouse model of obesity," Circulation, vol. 127, no. 1, pp. 74-85, 2013.

[113] B. Bostick, J. Habibi, L. Ma et al., "Dipeptidyl peptidase inhibition prevents diastolic dysfunction and reduces myocardial fibrosis in a mouse model of Western diet induced obesity," Metabolism: Clinical and Experimental, vol. 63, no. 8, pp. 10001011, 2014.

[114] Z. Ma, J. Zhang, E. Ji, G. Cao, G. Li, and L. Chu, "Rho kinase inhibition by fasudil exerts antioxidant effects in hypercholesterolemic rats," Clinical and Experimental Pharmacology \& Physiology, vol. 38, no. 10, pp. 688-694, 2011.

[115] N. Wu, X. Zhang, and D. Jia, "High-dose fasudil preconditioning and postconditioning attenuate myocardial ischemiareperfusion injury in hypercholesterolemic rats," Molecular Medicine Reports, vol. 9, no. 2, pp. 560-566, 2014.

[116] N. Wu, W. Li, W. Shu, Y. Lv, and D. Jia, "Inhibition of Rho-kinase by fasudil restores the cardioprotection of ischemic postconditioninng in hypercholesterolemic rat heart," Molecular Medicine Reports, vol. 10, no. 5, pp. 2517-2524, 2014.

[117] J. M. Downey and M. V. Cohen, "Why do we still not have cardioprotective drugs?” Circulation Journal, vol. 73, no. 7, pp. 1171-1177, 2009.

[118] T. Csont, M. Sárközy, G. Szcs et al., "Effect of a multivitamin preparation supplemented with phytosterol on serum lipids and infarct size in rats fed with normal and high cholesterol diet," Lipids in Health and Disease, vol. 12, article 138, 2013.

[119] U. N. Das, "Folic acid says NO to vascular diseases," Nutrition, vol. 19, no. 7-8, pp. 686-692, 2003.
[120] P. A. Ribeiro Jorge, M. R. Osaki, E. De Almeida, L. C. Neto, and K. Metze, "Effects of vitamin E on endothelium-dependent coronary flow in hypercholesterolemic dogs," Atherosclerosis, vol. 126, no. 1, pp. 43-51, 1996.

[121] H. M. O.-V. Straaten, A. M. E. S.-D. Man, and M. C. de Waard, "Vitamin C revisited," Critical Care, vol. 18, no. 4, article 460, 2014.

[122] K. Prasad, E. D. Mc Nair, A. M. Qureshi, and G. CasperBell, "Vitamin e slows the progression of hypercholesterolemiainduced oxidative stress in heart, liver and kidney," Molecular and Cellular Biochemistry, vol. 368, no. 1-2, pp. 181-187, 2012.

[123] M. Pravenec, V. Kožich, J. Krijt et al., "Folate deficiency is associated with oxidative stress, increased blood pressure, and insulin resistance in spontaneously hypertensive rats," American Journal of Hypertension, vol. 26, no. 1, pp. 135-140, 2013.

[124] L. S. E. Silva, A. M. de Miranda, C. L. de Brito Magalhães, R. C. Dos Santos, M. L. Pedrosa, and M. E. Silva, "Diet supplementation with beta-carotene improves the serum lipid profile in rats fed a cholesterol-enriched diet," Journal of Physiology and Biochemistry, vol. 69, no. 4, pp. 811-820, 2013.

[125] Y. B. Solanki and R. V. Bhatt, "Effects of antioxidant vitamins along with atorvastatin and atorvastatin-niacin combination on diet-induced hypercholesterolemia in rats," International Journal of Physiology, Pathophysiology and Pharmacology, vol. 2, no. 1, pp. 57-63, 2010.

[126] X.-Y. Zhu, M. Rodriguez-Porcel, M. D. Bentley et al., "Antioxidant intervention attenuates myocardial neovascularization in hypercholesterolemia," Circulation, vol. 109, no. 17, pp. 21092115, 2004.

[127] S. D. Bellows, S. L. Hale, B. Z. Simkhovich, G. L. Kay, and R. A. Kloner, "Do antioxidant vitamins reduce infarct size following acute myocardial ischemia/reperfusion?" Cardiovascular Drugs and Therapy, vol. 9, no. 1, pp. 117-123, 1995.

[128] H. H. Klein, S. Pich, K. Nebendahl, P. Niedmann, and P. SchuffWerner, "Acute treatment with vitamin E does not protect the regionally ischemic, reperfused porcine heart," Basic Research in Cardiology, vol. 86, no. 1, pp. 32-39, 1991.

[129] N. K. Saleh and H. A. Saleh, "Protective effects of vitamin E against myocardial ischemia/reperfusion injury in rats," Saudi Medical Journal, vol. 31, no. 2, pp. 142-147, 2010.

[130] O. Firuzi, R. Miri, M. Tavakkoli, and L. Saso, "Antioxidant therapy: current status and future prospects," Current Medicinal Chemistry, vol. 18, no. 25, pp. 3871-3888, 2011.

[131] T. Münzel, T. Gori, R. M. Bruno, and S. Taddei, "Is oxidative stress a therapeutic target in cardiovascular disease?" European Heart Journal, vol. 31, no. 22, pp. 2741-2749, 2010.

[132] S. R. Steinhubl, "Genotyping, clopidogrel metabolism, and the search for the therapeutic window of thienopyridines," Circulation, vol. 121, no. 4, pp. 481-483, 2010.

[133] F. L. Crane, "Biochemical functions of coenzyme Q10," The Journal of the American College of Nutrition, vol. 20, no. 6, pp. 591-598, 2001.

[134] B. Kaltschmidt, T. Sparna, and C. Kaltschmidt, "Activation of NF- $\kappa$ B by reactive oxygen intermediates in the nervous system," Antioxidants \& Redox Signaling, vol. 1, no. 2, pp. 129-144, 1999.

[135] A. Kumar, H. Kaur, P. Devi, and V. Mohan, "Role of coenzyme Q10 (CoQ10) in cardiac disease, hypertension and Meniere-like syndrome," Pharmacology \& Therapeutics, vol. 124, no. 3, pp. 259-268, 2009. 
[136] M. Mohseni, M. R. Vafa, S. J. Hajimiresmail et al., "Effects of coenzyme q10 supplementation on serum lipoproteins, plasma fibrinogen, and blood pressure in patients with hyperlipidemia and myocardial infarction," Iranian Red Crescent Medical Journal, vol. 16, no. 10, Article ID e16433, 2014.

[137] Y. K. Yang, L. P. Wang, L. Chen et al., "Coenzyme Q10 treatment of cardiovascular disorders of ageing including heart failure, hypertension and endothelial dysfunction," Clinica Chimica Acta, vol. 450, pp. 83-89, 2015.

[138] G. P. Littarru and P. Langsjoen, "Coenzyme Q10 and statins: biochemical and clinical implications," Mitochondrion, vol. 7, supplement, pp. S168-S174, 2007.

[139] A. M. Andres, G. Hernandez, P. Lee et al., "Mitophagy is required for acute cardioprotection by simvastatin," Antioxidants and Redox Signaling, vol. 21, no. 14, pp. 1960-1973, 2014.

[140] R. S. Ahmad, M. S. Butt, M. T. Sultan et al., "Preventive role of green tea catechins from obesity and related disorders especially hypercholesterolemia and hyperglycemia," Journal of Translational Medicine, vol. 13, article 79, 2015.

[141] P. V. Anandh Babu, K. E. Sabitha, and C. S. Shyamaladevi, "Green tea extract impedes dyslipidaemia and development of cardiac dysfunction in streptozotocin-diabetic rats," Clinical and Experimental Pharmacology and Physiology, vol. 33, no. 12, pp. 1184-1189, 2006.

[142] T. T. C. Yang and M. W. L. Koo, "Hypocholesterolemic effects of Chinese tea," Pharmacological Research, vol. 35, no. 6, pp. 505512, 1997.

[143] S. Yousaf, M. S. Butt, H. A. R. Suleria, and M. J. Iqbal, "The role of green tea extract and powder in mitigating metabolic syndromes with special reference to hyperglycemia and hypercholesterolemia," Food and Function, vol. 5, no. 3, pp. 545-556, 2014.

[144] K. Imai and K. Nakachi, "Cross sectional study of effects of drinking green tea on cardiovascular and liver diseases," British Medical Journal, vol. 310, no. 6981, pp. 693-696, 1995.

[145] S. Kono, K. Shinchi, N. Ikeda, F. Yanai, and K. Imanishi, "Green tea consumption and serum lipid profiles: a cross-sectional study in Northern Kyushu, Japan," Preventive Medicine, vol. 21, no. 4, pp. 526-531, 1992.

[146] T. Chisaka, H. Matsuda, Y. Kubomura, M. Mochizuki, J. Yamahara, and H. Fujimura, "The effect of crude drugs on experimental hypercholesteremia: mode of action of (-)epigallocatechin gallate in tea leaves," Chemical \& Pharmaceutical Bulletin, vol. 36, no. 1, pp. 227-233, 1988.

[147] X.-X. Zheng, Y.-L. Xu, S.-H. Li, X.-X. Liu, R. Hui, and X.H. Huang, "Green tea intake lowers fasting serum total and LDL cholesterol in adults: a meta-analysis of 14 randomized controlled trials," American Journal of Clinical Nutrition, vol. 94, no. 2, pp. 601-610, 2011.

[148] P. Bogdanski, J. Suliburska, M. Szulinska, M. Stepien, D. Pupek-Musialik, and A. Jablecka, "Green tea extract reduces blood pressure, inflammatory biomarkers, and oxidative stress and improves parameters associated with insulin resistance in obese, hypertensive patients," Nutrition Research, vol. 32, no. 6, pp. 421-427, 2012.

[149] P. Mehra, A. Koul, and D. D. Bansal, "Studies on antioxidant role of (+)-catechin hydrate in high sucrose high fat diet induced oxidative stress," American Journal of Biomedical Sciences, vol. 5, no. 2, pp. 161-170, 2013.
[150] B. Qin, M. M. Polansky, D. Harry, and R. A. Anderson, "Green tea polyphenols improve cardiac muscle mRNA and protein levels of signal pathways related to insulin and lipid metabolism and inflammation in insulin-resistant rats," Molecular Nutrition and Food Research, vol. 54, supplement, pp. S14-S23, 2010.

[151] V. S. Kumaran, K. Arulmathi, and P. Kalaiselvi, "Senescence mediated redox imbalance in cardiac tissue: antioxidant rejuvenating potential of green tea extract," Nutrition, vol. 25, no. 7-8, pp. 847-854, 2009.

[152] M. Hirai, Y. Hotta, N. Ishikawa et al., "Protective effects of EGCg or GCg, a green tea catechin epimer, against postischemic myocardial dysfunction in guinea-pig hearts," Life Sciences, vol. 80, no. 11, pp. 1020-1032, 2007.

[153] J.-I. Suzuki, M. Ogawa, Y. Maejima et al., “Tea catechins attenuate chronic ventricular remodeling after myocardial ischemia in rats," Journal of Molecular and Cellular Cardiology, vol. 42, no. 2, pp. 432-440, 2007.

[154] Q. Zhang, L.-Q. Hu, C.-S. Yin et al., "Catechin ameliorates cardiac dysfunction in rats with chronic heart failure by regulating the balance between Th17 and Treg cells," Inflammation Research, vol. 63, no. 8, pp. 619-628, 2014.

[155] J.-I. Suzuki, M. Ogawa, H. Futamatsu, H. Kosuge, Y. M. Sagesaka, and M. Isobe, "Tea catechins improve left ventricular dysfunction, suppress myocardial inflammation and fibrosis, and alter cytokine expression in rat autoimmune myocarditis," European Journal of Heart Failure, vol. 9, no. 2, pp. 152-159, 2007.

[156] I. E. Blasig, H. Lowe, and B. Ebert, "Radical trapping and lipid peroxidation during myocardial reperfusion injuryradical scavenging by troxerutin in comparison to mannitol," Biomedica Biochimica Acta, vol. 46, no. 8-9, pp. S539-S544, 1987.

[157] R. Geetha, B. Yogalakshmi, S. Sreeja, K. Bhavani, and C. V. Anuradha, "Troxerutin suppresses lipid abnormalities in the heart of high-fat-high-fructose diet-fed mice," Molecular and Cellular Biochemistry, vol. 387, no. 1-2, pp. 123-134, 2014.

[158] R. Geetha, M. K. Radika, E. Priyadarshini, K. Bhavani, and C. V. Anuradha, "Troxerutin reverses fibrotic changes in the myocardium of high-fat high-fructose diet-fed mice," Molecular and Cellular Biochemistry, vol. 407, no. 1, pp. 263-279, 2015.

[159] L. Liu, Y. Mu, W. Han, and C. Wang, "Association of hypercholesterolemia and cardiac function evaluated by speckle tracking echocardiography in a rabbit model," Lipids in Health and Disease, vol. 13, article 28, 2014.

[160] Y. Wang, Z. Z. Zhang, Y. Wu, J. J. Ke, X. H. He, and Y. L. Wang, "Quercetin postconditioning attenuates myocardial ischemia/reperfusion injury in rats through the PI3K/Akt pathway," Brazilian Journal of Medical and Biological Research, vol. 46, no. 10, pp. 861-867, 2013.

[161] H.-B. Jin, Y.-B. Yang, Y.-L. Song, Y.-C. Zhang, and Y.-R. Li, "Protective roles of quercetin in acute myocardial ischemia and reperfusion injury in rats," Molecular Biology Reports, vol. 39, no. 12, pp. 11005-11009, 2012.

[162] A. Annapurna, C. S. Reddy, R. B. Akondi, and S. R. C. Rao, "Cardioprotective actions of two bioflavonoids, quercetin and rutin, in experimental myocardial infarction in both normal and streptozotocin-induced type I diabetic rats," The Journal of Pharmacy and Pharmacology, vol. 61, no. 10, pp. 1365-1374, 2009.

[163] L. L. Wan, J. Xia, D. Ye, J. Liu, J. Chen, and G. Wang, "Effects of quercetin on gene and protein expression of NOX and 
NOS after myocardial ischemia and reperfusion in rabbit," Cardiovascular Therapeutics, vol. 27, no. 1, pp. 28-33, 2009.

[164] S. K. Panchal, H. Poudyal, and L. Brown, "Quercetin ameliorates cardiovascular, hepatic, and metabolic changes in diet-induced metabolic syndrome in rats," Journal of Nutrition, vol. 142, no. 6, pp. 1026-1032, 2012.

[165] A. D. Mariee, G. M. Abd-Allah, and H. A. El-Beshbishy, "Protective effect of dietary flavonoid quercetin against lipemicoxidative hepatic injury in hypercholesterolemic rats," Pharmaceutical Biology, vol. 50, no. 8, pp. 1019-1025, 2012.

[166] C. Kamada, E. L. da Silva, M. Ohnishi-Kameyama, J.-H. Moon, and J. Terao, "Attenuation of lipid peroxidation and hyperlipidemia by quercetin glucoside in the aorta of high cholesterolfed rabbit," Free Radical Research, vol. 39, no. 2, pp. 185-194, 2005.

[167] S. Juźwiak, J. Wójcicki, K. Mokrzycki et al., "Effect of quercetin on experimental hyperlipidemia and atherosclerosis in rabbits," Pharmacological Reports, vol. 57, no. 5, pp. 604-609, 2005.

[168] E. Ulasova, J. Perez, B. G. Hill et al., "Quercetin prevents left ventricular hypertrophy in the Apo E knockout mouse," Redox Biology, vol. 1, no. 1, pp. 381-386, 2013.

[169] S. Milton Prabu, M. Muthumani, and K. Shagirtha, "Quercetin potentially attenuates cadmium induced oxidative stress mediated cardiotoxicity and dyslipidemia in rats," European Review for Medical and Pharmacological Sciences, vol. 17, no. 5, pp. 582595, 2013.

[170] A. Ziaee, F. Zamansoltani, M. Nassiri-Asl, and E. Abbasi, "Effects of rutin on lipid profile in hypercholesterolaemic rats," Basic and Clinical Pharmacology and Toxicology, vol. 104, no. 3, pp. 253-258, 2009.

[171] S. S. Al-Rejaie, A. M. Aleisa, M. M. Sayed-Ahmed et al., "Protective effect of rutin on the antioxidant genes expression in hypercholestrolemic male Westar rat," BMC Complementary and Alternative Medicine, vol. 13, article 136, 2013.

[172] V. Umarani, S. Muvvala, A. Ramesh, B. V. Lakshmi, and N. Sravanthi, "Rutin potentially attenuates fluoride-induced oxidative stress-mediated cardiotoxicity, blood toxicity and dyslipidemia in rats," Toxicology Mechanisms and Methods, vol. 25, no. 2, pp. 143-149, 2015.

[173] S. K. Panchal, H. Poudyal, T. V. Arumugam, and L. Brown, "Rutin attenuates metabolic changes, nonalcoholic steatohepatitis, and cardiovascular remodeling in high-carbohydrate, high-fat diet-fed rats," Journal of Nutrition, vol. 141, no. 6, pp. 1062-1069, 2011.

[174] K. M. Krishna, A. Annapurna, G. S. Gopal et al., "Partial reversal by rutin and quercetin of impaired cardiac function in streptozotocin-induced diabetic rats," Canadian Journal of Physiology and Pharmacology, vol. 83, no. 4, pp. 343-355, 2005.

[175] V. Krečman, N. Škottová, D. Walterová, J. Ulrichová, and V. Šimének, "Silymarin inhibits the development of diet-induced hypercholesterolemia in rats," Planta Medica, vol. 64, no. 2, pp. 138-142, 1998.

[176] M.-C. Lin, S.-H. Kao, P.-J. Chung, K.-C. Chan, M.-Y. Yang, and C.-J. Wang, "Improvement for high fat diet-induced hepatic injuries and oxidative stress by flavonoid-enriched extract from Nelumbo nucifera leaf," Journal of Agricultural and Food Chemistry, vol. 57, no. 13, pp. 5925-5932, 2009.

[177] N. Škottová, L. Kazdová, O. Oliyarnyk, R. Večeřa, L. Sobolová, and J. Ulrichová, "Phenolics-rich extracts from Silybum marianum and Prunella vulgaris reduce a high-sucrose diet induced oxidative stress in hereditary hypertriglyceridemic rats," Pharmacological Research, vol. 50, no. 2, pp. 123-130, 2004.

[178] N. Škottová, R. Večeřa, K. Urbánek, P. Váňa, D. Walterová, and L. Cvak, "Effects of polyphenolic fraction of silymarin on lipoprotein profile in rats fed cholesterol-rich diets," Pharmacological Research, vol. 47, no. 1, pp. 17-26, 2003.

[179] P. R. Rao and R. K. Viswanath, "Cardioprotective activity of silymarin in ischemia-reperfusion-induced myocardial infarction in albino rats," Experimental and Clinical Cardiology, vol. 12, no. 4, pp. 179-187, 2007.

[180] I. Anestopoulos, A. Kavo, I. Tentes et al., "Silibinin protects H9c2 cardiac cells from oxidative stress and inhibits phenylephrine-induced hypertrophy: potential mechanisms," The Journal of Nutritional Biochemistry, vol. 24, no. 3, pp. 586594, 2013.

[181] M. Muthumani and S. M. Prabu, "Silibinin potentially attenuates arsenic-induced oxidative stress mediated cardiotoxicity and dyslipidemia in rats," Cardiovascular Toxicology, vol. 14, no. 1, pp. 83-97, 2014.

[182] M. A. Alam, K. Kauter, and L. Brown, "Naringin improves diet-induced cardiovascular dysfunction and obesity in high carbohydrate, high fat diet-fed rats," Nutrients, vol. 5, no. 3, pp. 637-650, 2013.

[183] A. Chanet, D. Milenkovic, C. Deval et al., "Naringin, the major grapefruit flavonoid, specifically affects atherosclerosis development in diet-induced hypercholesterolemia in mice," The Journal of Nutritional Biochemistry, vol. 23, no. 5, pp. 469477, 2012.

[184] S.-H. Bok, S.-H. Lee, Y.-B. Park et al., "Plasma and hepatic cholesterol and hepatic activities of 3-hydroxy-3- methylglutaryl-CoA reductase and acyl CoA: cholesterol transferase are lower in rats fed citrus peel extract or a mixture of citrus bioflavonoids," The Journal of Nutrition, vol. 129, no. 6, pp. 1182$1185,1999$.

[185] S.-Y. Kim, H.-J. Kim, M.-K. Lee et al., "Naringin timedependently lowers hepatic cholesterol biosynthesis and plasma cholesterol in rats fed high-fat and high-cholesterol diet," Journal of Medicinal Food, vol. 9, no. 4, pp. 582-586, 2006.

[186] S.-M. Jeon, Y. B. Park, and M.-S. Choi, "Antihypercholesterolemic property of naringin alters plasma and tissue lipids, cholesterol-regulating enzymes, fecal sterol and tissue morphology in rabbits," Clinical Nutrition, vol. 23, no. 5, pp. 1025-1034, 2004.

[187] M. T. Monforte, A. Trovato, S. Kirjavainen, A. M. Forestieri, E. M. Galati, and R. B. Lo Curto, "Biological effects of hesperidin, a Citrus flavonoid. (note II): hypolipidemic activity on experimental hypercholesterolemia in rat," Farmaco, vol. 50, no. 9, pp. 595-599, 1995.

[188] S.-H. Lee, T.-S. Jeong, Y. B. Park, Y.-K. Kwon, M.-S. Choi, and S.-H. Bok, "Hypocholesterolemic effect of hesperetin mediated by inhibition of 3- hydroxy-3-methylgultaryl coenzyme A reductase and acyl coenzyme A: Cholesterol acyltransferase in rats fed high-cholesterol diet," Nutrition Research, vol. 19, no. 8, pp. 1245-1258, 1999.

[189] U. J. Jung, H. J. Kim, J. S. Lee et al., "Naringin supplementation lowers plasma lipids and enhances erythrocyte antioxidant enzyme activities in hypercholesterolemic subjects," Clinical Nutrition, vol. 22, no. 6, pp. 561-568, 2003. 
[190] I. Demonty, Y. Lin, Y. E. M. P. Zebregs et al., “The citrus flavonoids hesperidin and naringin do not affect serum cholesterol in moderately hypercholesterolemic men and women," The Journal of Nutrition, vol. 140, no. 9, pp. 1615-1620, 2010.

[191] Y. Chtourou, A. B. Slima, M. Makni, R. Gdoura, and H. Fetoui, "Naringenin protects cardiac hypercholesterolemiainduced oxidative stress and subsequent necroptosis in rats," Pharmacological Reports, vol. 67, no. 6, pp. 1090-1097, 2015.

[192] P. P. Trivedi, S. Kushwaha, D. N. Tripathi, and G. B. Jena, "Cardioprotective effects of hesperetin against doxorubicininduced oxidative stress and DNA damage in rat," Cardiovascular Toxicology, vol. 11, no. 3, pp. 215-225, 2011.

[193] P. Selvaraj and K. V. Pugalendi, "Hesperidin, a flavanone glycoside, on lipid peroxidation and antioxidant status in experimental myocardial ischemic rats," Redox Report, vol. 15, no. 5, pp. 217-223, 2010.

[194] H. Y. Yu, J. H. Ahn, S. W. Park, and Y.-S. Jung, "Preventive effect of Yuzu and hesperidin on left ventricular remodeling and dysfunction in rat permanent left anterior descending coronary artery occlusion model," PLoS ONE, vol. 10, no. 1, Article ID el10596, 2015.

[195] J.-T. Hwang, D. Y. Kwon, O. J. Park, and M. S. Kim, "Resveratrol protects ROS-induced cell death by activating AMPK in H9c2 cardiac muscle cells," Genes \& Nutrition, vol. 2, no. 4, pp. 323326, 2008.

[196] X. L. Louis, S. J. Thandapilly, S. K. MohanKumar et al., “Treatment with low-dose resveratrol reverses cardiac impairment in obese prone but not in obese resistant rats," The Journal of Nutritional Biochemistry, vol. 23, no. 9, pp. 1163-1169, 2012.

[197] S. V. Penumathsa, M. Thirunavukkarasu, S. Koneru et al., "Statin and resveratrol in combination induces cardioprotection against myocardial infarction in hypercholesterolemic rat," Journal of Molecular and Cellular Cardiology, vol. 42, no. 3, pp. 508-516, 2007.

[198] M. P. Robich, L. M. Chu, T. A. Burgess et al., "Resveratrol preserves myocardial function and perfusion in remote nonischemic myocardium in a swine model of metabolic syndrome," Journal of the American College of Surgeons, vol. 215, no. 5, pp. 681-689, 2012.

[199] M. P. Robich, R. M. Osipov, L. M. Chu et al., "Resveratrol modifies risk factors for coronary artery disease in swine with metabolic syndrome and myocardial ischemia," European Journal of Pharmacology, vol. 664, no. 1-3, pp. 45-53, 2011.

[200] M. P. Robich, R. M. Osipov, R. Nezafat et al., "Resveratrol improves myocardial perfusion in a swine model of hypercholesterolemia and chronic myocardial ischemia," Circulation, vol. 122, no. 11, pp. S142-S149, 2010.

[201] Y. Gao, L. Kang, C. Li et al., "Resveratrol ameliorates diabetesinduced cardiac dysfunction through AT1R-ERK/p38 MAPK signaling pathway," Cardiovascular Toxicology, 2015.

[202] K. Charradi, M. Mahmoudi, S. Elkahoui, F. Limam, and E. Aouani, "Grape seed and skin extract mitigates heart and liver oxidative damage induced by a high-fat diet in the rat: gender dependency," Canadian Journal of Physiology and Pharmacology, vol. 91, no. 12, pp. 1076-1085, 2013.

[203] K. Charradi, H. Sebai, S. Elkahoui, F. Ben Hassine, F. Limam, and E. Aouani, "Grape seed extract alleviates high-fat dietinduced obesity and heart dysfunction by preventing cardiac siderosis," Cardiovascular Toxicology, vol. 11, no. 1, pp. 28-37, 2011.
[204] S. J. Lee, S. K. Choi, and J. S. Seo, "Grape skin improves antioxidant capacity in rats fed a high fat diet," Nutrition Research and Practice, vol. 3, no. 4, pp. 279-285, 2009.

[205] Y. Du, H. Guo, and H. Lou, "Grape seed polyphenols protect cardiac cells from apoptosis via induction of endogenous antioxidant enzymes," Journal of Agricultural and Food Chemistry, vol. 55, no. 5, pp. 1695-1701, 2007.

[206] T. Pataki, I. Bak, P. Kovacs, D. Bagchi, D. K. Das, and A. Tosaki, "Grape seed proanthocyanidins improved cardiac recovery during reperfusion after ischemia in isolated rat hearts," American Journal of Clinical Nutrition, vol. 75, no. 5, pp. 894-899, 2002.

[207] M. Thiruchenduran, N. A. Vijayan, J. K. Sawaminathan, and S. N. Devaraj, "Protective effect of grape seed proanthocyanidins against cholesterol cholic acid diet-induced hypercholesterolemia in rats," Cardiovascular Pathology, vol. 20, no. 6, pp. 361-368, 2011.

[208] I. Bak, I. Lekli, B. Juhasz et al., "Isolation and analysis of bioactive constituents of sour cherry (Prunus cerasus) seed kernel: an emerging functional food," Journal of Medicinal Food, vol. 13, no. 4, pp. 905-910, 2010.

[209] I. Bak, I. Lekli, B. Juhasz et al., "Cardioprotective mechanisms of Prunus cerasus (sour cherry) seed extract against ischemiareperfusion-induced damage in isolated rat hearts," The American Journal of Physiology-Heart and Circulatory Physiology, vol. 291, no. 3, pp. H1329-H1336, 2006.

[210] B. Juhasz, A. Kertész, J. Balla et al., "Cardioprotective effects of sour cherry seed extract (SCSE) on the hypercholesterolemic rabbit heart," Current Pharmaceutical Design, vol. 19, no. 39, pp. 6896-6905, 2013.

[211] A. Czompa, A. Gyongyosi, A. Czegledi et al., "Cardioprotection afforded by sour cherry seed kernel: the role of heme oxygenase1," Journal of Cardiovascular Pharmacology, vol. 64, no. 5, pp. 412-419, 2014.

[212] A. J. Esterhuyse, E. F. du Toit, A. J. S. Benadeè, and J. Van Rooyen, "Dietary red palm oil improves reperfusion cardiac function in the isolated perfused rat heart of animals fed a high cholesterol diet," Prostaglandins Leukotrienes and Essential Fatty Acids, vol. 72, no. 3, pp. 153-161, 2005.

[213] J. van Rooyen, A. J. Esterhuyse, A.-M. Engelbrecht, and E. F. Du Toit, "Health benefits of a natural carotenoid rich oil: a proposed mechanism of protection against ischaemia/reperfusion injury," Asia Pacific Journal of Clinical Nutrition, vol. 17, supplement 1, pp. 316-319, 2008.

[214] E. Serbinova, V. Kagan, D. Han, and L. Packer, "Free radical recycling and intramembrane mobility in the antioxidant properties of alpha-tocopherol and alpha-tocotrienol," Free Radical Biology and Medicine, vol. 10, no. 5, pp. 263-275, 1991.

[215] G. Szucs, D. J. Bester, K. Kupai et al., "Dietary red palm oil supplementation decreases infarct size in cholesterol fed rats," Lipids in Health and Disease, vol. 10, article 103, 2011.

[216] D. J. Bester, K. Kupai, T. Csont et al., "Dietary red palm oil supplementation reduces myocardial infarct size in an isolated perfused rat heart model," Lipids in Health and Disease, vol. 9, article 64, 2010.

[217] E. Katengua-Thamahane, J. L. Marnewick, O. R. Ajuwon et al., "The combination of red palm oil and rooibos show antiinflammatory effects in rats," Journal of Inflammation, vol. 11, article 41, 2014. 
[218] E. Katengua-Thamahane, A.-M. Engelbrecht, A. J. Esterhuyse, and J. Van Rooyen, "Inhibition of Akt attenuates RPO-induced cardioprotection," Cardiology Research and Practice, vol. 2012, Article ID 392457, 9 pages, 2012.

[219] J. S. Esterhuyse, J. van Rooyen, H. Strijdom, D. Bester, and E. F. du Toit, "Proposed mechanisms for red palm oil induced cardioprotection in a model of hyperlipidaemia in the rat," Prostaglandins Leukotrienes and Essential Fatty Acids, vol. 75, no. 6, pp. 375-384, 2006.

[220] M. J. Kruger, A.-M. Engelbrecht, J. Esterhuyse, E. du Toit, and J. van Rooyen, "Dietary red palm oil reduces ischaemiareperfusion injury in rats fed a hypercholesterolaemic diet," The British Journal of Nutrition, vol. 97, no. 4, pp. 653-660, 2007.

[221] S. P. Romaine, M. Tomaszewski, G. Condorelli, and N. J. Samani, "MicroRNAs in cardiovascular disease: an introduction for clinicians," Heart, vol. 101, no. 12, pp. 921-928, 2015.

[222] E. J. Hennessy and K. J. Moore, "Using microRNA as an alternative treatment for hyperlipidemia and cardiovascular disease: cardio-miRs in the pipeline," Journal of Cardiovascular Pharmacology, vol. 62, no. 3, pp. 247-254, 2013.

[223] K. Ono, T. Horie, T. Nishino, O. Baba, Y. Kuwabara, and T. Kimura, "Micrornas and high-density lipoprotein cholesterol metabolism," International Heart Journal, vol. 56, no. 4, pp. 365371, 2015.

[224] M. Notari, J. Pulecio, and Á. Raya, "Update on the pathogenic implications and clinical potential of microRNAs in cardiac disease," BioMed Research International, vol. 2015, Article ID 105620, 15 pages, 2015.

[225] R. A. Boon and S. Dimmeler, "MicroRNAs in myocardial infarction," Nature Reviews Cardiology, vol. 12, no. 3, pp. 135142, 2015.

[226] E. M. Small, R. J. A. Frost, and E. N. Olson, "MicroRNAs add a new dimension to cardiovascular disease," Circulation, vol. 121, no. 8, pp. 1022-1032, 2010.

[227] S. K. Gupta, M. T. Piccoli, and T. Thum, "Non-coding RNAs in cardiovascular ageing," Ageing Research Reviews, vol. 17, pp. 7985, 2014.

[228] J. Viereck, C. Bang, A. Foinquinos, and T. Thum, "Regulatory RNAs and paracrine networks in the heart," Cardiovascular Research, vol. 102, no. 2, pp. 290-301, 2014.

[229] A. Dávalos and C. Fernández-Hernando, "From evolution to revolution: miRNAs as pharmacological targets for modulating cholesterol efflux and reverse cholesterol transport," Pharmacological Research, vol. 75, pp. 60-72, 2013.

[230] M. F. Figueira, G. Monnerat-Cahli, E. Medei et al., "MicroRNAs: potential therapeutic targets in diabetic complications of the cardiovascular and renal systems," Acta Physiologica, vol. 211, no. 3, pp. 491-500, 2014.

[231] S. Rawal, P. Manning, and R. Katare, "Cardiovascular microRNAs: as modulators and diagnostic biomarkers of diabetic heart disease," Cardiovascular Diabetology, vol. 13, article 44, 2014.

[232] W. A. Heggermont and S. Heymans, "microRNAs are involved in end-organ damage during hypertension," Hypertension, vol. 60, no. 5, pp. 1088-1093, 2012.

[233] L. Shi, J. Liao, B. Liu, F. Zeng, and L. Zhang, "Mechanisms and therapeutic potential of microRNAs in hypertension," Drug Discovery Today, 2015.
[234] M. Nazari-Jahantigh, V. Egea, A. Schober, and C. Weber, "MicroRNA-specific regulatory mechanisms in atherosclerosis," Journal of Molecular and Cellular Cardiology, 2014.

[235] A. Schober, M. Nazari-Jahantigh, and C. Weber, "microRNAmediated mechanisms of the cellular stress response in atherosclerosis," Nature Reviews Cardiology, vol. 12, no. 6, pp. 361-374, 2015.

[236] L. Yao, Z. Liu, J. Zhu, B. Li, C. Chai, and Y. Tian, "Clinical evaluation of circulating microRNA-25 level change in sepsis and its potential relationship with oxidative stress," International Journal of Clinical and Experimental Pathology, vol. 8, no. 7, pp. 7675-7684, 2015.

[237] E. Dirkx, M. M. Gladka, L. E. Philippen et al., "Nfat and miR-25 cooperate to reactivate the transcription factor Hand2 in heart failure," Nature Cell Biology, vol. 15, no. 11, pp. 1282-1293, 2013.

[238] C. Wahlquist, D. Jeong, A. Rojas-Muñoz et al., "Inhibition of miR-25 improves cardiac contractility in the failing heart," Nature, vol. 508, no. 7497, pp. 531-535, 2014.

[239] H. E. Azzouzi, S. Leptidis, P. A. Doevendans, and L. J. De Windt, "HypoxamiRs: regulators of cardiac hypoxia and energy metabolism," Trends in Endocrinology \& Metabolism, vol. 26, no. 9, pp. 502-508, 2015.

[240] X. Cheng, C.-H. Ku, and R. C. M. Siow, "Regulation of the Nrf2 antioxidant pathway by microRNAs: new players in micromanaging redox homeostasis," Free Radical Biology \& Medicine, vol. 64, pp. 4-11, 2013.

[241] A. Magenta, S. Greco, C. Gaetano, and F. Martelli, "Oxidative stress and microRNAs in vascular diseases," International Journal of Molecular Sciences, vol. 14, no. 9, pp. 17319-17346, 2013.

[242] Y. C. Chan, J. Banerjee, S. Y. Choi, and C. K. Sen, "miR-210: the master hypoxamir," Microcirculation, vol. 19, no. 3, pp. 215-223, 2012.

[243] A. Eulalio, M. Mano, M. D. Ferro et al., "Functional screening identifies miRNAs inducing cardiac regeneration," Nature, vol. 492, no. 7429, pp. 376-381, 2012.

[244] E. van Rooij and S. Kauppinen, "Development of microRNA therapeutics is coming of age," EMBO Molecular Medicine, vol. 6, no. 7, pp. 851-864, 2014.

[245] C. Szabó, H. Ischiropoulos, and R. Radi, "Peroxynitrite: biochemistry, pathophysiology and development of therapeutics," Nature Reviews Drug Discovery, vol. 6, no. 8, pp. 662-680, 2007.

[246] A. Ónody, C. Csonka, Z. Giricz, and P. Ferdinandy, "Hyperlipidemia induced by a cholesterol-rich diet leads to enhanced peroxynitrite formation in rat hearts," Cardiovascular Research, vol. 58, no. 3, pp. 663-670, 2003.

[247] C.-S. Huang, T. Kawamura, Y. Toyoda, and A. Nakao, "Recent advances in hydrogen research as a therapeutic medical gas," Free Radical Research, vol. 44, no. 9, pp. 971-982, 2010.

[248] R. Hyspler, A. Ticha, H. Schierbeek, A. Galkin, Z. Zadak, and H. Reddy, "The evaluation and quantitation of dihydrogen metabolism using deuterium isotope in rats," PLOS ONE, vol. 10, no. 6, Article ID e0130687, 2015.

[249] S. Wu, L. Zhu, J. Yang et al., "Hydrogen-containing saline attenuates doxorubicin-induced heart failure in rats," Die Pharmazie, vol. 69, no. 8, pp. 633-636, 2014.

[250] F. Wu, Y. Qiu, G. Ye et al., “Treatment with hydrogen molecule attenuates cardiac dysfunction in streptozotocin-induced diabetic mice," Cardiovascular Pathology, vol. 24, no. 5, pp. 294303, 2015. 
[251] A. Nakao, D. J. Kaczorowski, Y. Wang et al., "Amelioration of rat cardiac cold ischemia/reperfusion injury with inhaled hydrogen or carbon monoxide, or both," The Journal of Heart and Lung Transplantation, vol. 29, no. 5, pp. 544-553, 2010.

[252] Y.-S. Yu and H. Zheng, "Chronic hydrogen-rich saline treatment reduces oxidative stress and attenuates left ventricular hypertrophy in spontaneous hypertensive rats," Molecular and Cellular Biochemistry, vol. 365, no. 1-2, pp. 233-242, 2012.

[253] L. Jing, Y. Wang, X.-M. Zhao et al., "Cardioprotective effect of hydrogen-rich saline on isoproterenol-induced myocardial infarction in rats," Heart Lung and Circulation, vol. 24, no. 6, pp. 602-610, 2015.

[254] T. Hayashi, T. Yoshioka, K. Hasegawa et al., "Inhalation of hydrogen gas attenuates left ventricular remodeling induced by intermittent hypoxia in mice," The American Journal of Physiology-Heart and Circulatory Physiology, vol. 301, no. 3, pp. H1062-H1069, 2011.

[255] A. Nakao, Y. Toyoda, P. Sharma, M. Evans, and N. Guthrie, "Effectiveness of hydrogen rich water on antioxidant status of subjects with potential metabolic syndrome-an open label pilot study," Journal of Clinical Biochemistry and Nutrition, vol. 46, no. 2, pp. 140-149, 2010.

[256] G. Song, Q. Lin, H. Zhao et al., "Hydrogen activates ATPbinding cassette transporter A1-dependent efflux ex vivo and improves high-density lipoprotein function in patients with hypercholesterolemia: a double-blinded, randomized, and placebo-controlled trial," The Journal of Clinical Endocrinology and Metabolism, vol. 100, no. 7, pp. 2724-2733, 2015.

[257] G. Mancini, J. de Oliveira, M. A. Hort et al., "Diphenyl diselenide differently modulates cardiovascular redox responses in young adult and middle-aged low-density lipoprotein receptor knockout hypercholesterolemic mice," The Journal of Pharmacy and Pharmacology, vol. 66, no. 3, pp. 387-397, 2014.

[258] R. Matyal, L. Chu, F. Mahmood et al., "Neuropeptide Y improves myocardial perfusion and function in a swine model of hypercholesterolemia and chronic myocardial ischemia," Journal of Molecular and Cellular Cardiology, vol. 53, no. 6, pp. 891-898, 2012.

[259] R. Matyal, S. Sakamuri, A. Wang et al., "Local infiltration of neuropeptide $\mathrm{Y}$ as a potential therapeutic agent against apoptosis and fibrosis in a swine model of hypercholesterolemia and chronic myocardial ischemia," European Journal of Pharmacology, vol. 718, no. 1-3, pp. 261-270, 2013.

[260] W. Fan, A. R. Atkins, R. T. Yu, M. Downes, and R. M. Evans, "Road to exercise mimetics: targeting nuclear receptors in skeletal muscle," Journal of Molecular Endocrinology, vol. 51, no. 3, pp. T87-T100, 2013.

[261] A. Boveris and A. Navarro, "Systemic and mitochondrial adaptive responses to moderate exercise in rodents," Free Radical Biology and Medicine, vol. 44, no. 2, pp. 224-229, 2008.

[262] M. Bosma, "Lipid homeostasis in exercise," Drug Discovery Today, vol. 19, no. 7, pp. 1019-1023, 2014.

[263] J. L. Durstine and W. L. Haskell, "Effects of exercise training on plasma lipids and lipoproteins," Exercise and Sport Sciences Reviews, vol. 22, pp. 477-521, 1994.

[264] S. K. Powers, W. B. Nelson, and M. B. Hudson, "Exerciseinduced oxidative stress in humans: cause and consequences," Free Radical Biology \& Medicine, vol. 51, no. 5, pp. 942-950, 2011.
[265] S. K. Powers and M. J. Jackson, "Exercise-induced oxidative stress: cellular mechanisms and impact on muscle force production," Physiological Reviews, vol. 88, no. 4, pp. 1243-1276, 2008.

[266] S. Fittipaldi, I. Dimauro, N. Mercatelli, and D. Caporossi, "Role of exercise-induced reactive oxygen species in the modulation of heat shock protein response," Free Radical Research, vol. 48, no. 1, pp. 52-70, 2014.

[267] E. C. Gomes, A. N. Silva, and M. R. D. Oliveira, "Oxidants, antioxidants, and the beneficial roles of exercise-induced production of reactive species," Oxidative Medicine and Cellular Longevity, vol. 2012, Article ID 756132, 12 pages, 2012.

[268] P. Steinbacher and P. Eckl, "Impact of oxidative stress on exercising skeletal muscle," Biomolecules, vol. 5, no. 2, pp. 356377, 2015.

[269] R. F. Furchgott and J. V. Zawadzki, "The obligatory role of endothelial cells in the relaxation of arterial smooth muscle by acetylcholine," Nature, vol. 288, no. 5789, pp. 373-376, 1980.

[270] B. A. Kingwell, "Nitric oxide-mediated metabolic regulation during exercise: effects of training in health and cardiovascular disease," The FASEB Journal, vol. 14, no. 12, pp. 1685-1696, 2000.

[271] T. Michel and P. M. Vanhoutte, "Cellular signaling and NO production," Pflugers Archiv: European Journal of Physiology, vol. 459, no. 6, pp. 807-816, 2010.

[272] V. J. de Beer, D. Merkus, S. B. Bender et al., "Familial hypercholesterolemia impairs exercise-induced systemic vasodilation due to reduced NO bioavailability," Journal of Applied Physiology, vol. 115, no. 12, pp. 1767-1776, 2013.

[273] A. J. Maxwell, J. Niebauer, P. S. Lin, P. S. Tsao, D. Bernstein, and J. P. Cooke, "Hypercholesterolemia impairs exercise capacity in mice," Vascular Medicine, vol. 14, no. 3, pp. 249-257, 2009.

[274] S. B. Bender, V. J. de Beer, D. L. Tharp et al., "Reduced contribution of endothelin to the regulation of systemic and pulmonary vascular tone in severe familial hypercholesterolaemia," The Journal of Physiology, vol. 592, no. 8, pp. 1757-1769, 2014.

[275] D. J. Green, J. H. Walsh, A. Maiorana, V. Burke, R. R. Taylor, and J. G. O'Driscoll, "Comparison of resistance and conduit vessel nitric oxide-mediated vascular function in vivo: effects of exercise training," Journal of Applied Physiology, vol. 97, no. 2, pp. 749-758, 2004.

[276] P. A. Stapleton, A. G. Goodwill, M. E. James, R. W. Brock, and J. C. Frisbee, "Hypercholesterolemia and microvascular dysfunction: interventional strategies," Journal of Inflammation, vol. 7, article 54, 2010.

[277] M. A. Thompson, K. K. Henderson, C. R. Woodman et al., "Exercise preserves endothelium-dependent relaxation in coronary arteries of hypercholesterolemic male pigs," Journal of Applied Physiology, vol. 96, no. 3, pp. 1114-1126, 2004.

[278] K. K. Henderson, J. R. Turk, J. W. E. Rush, and M. H. Laughlin, "Endothelial function in coronary arterioles from pigs with early-stage coronary disease induced by high-fat, high-cholesterol diet: effect of exercise," Journal of Applied Physiology, vol. 97, no. 3, pp. 1159-1168, 2004.

[279] J. H. Walsh, G. Yong, C. Cheetham et al., "Effects of exercise training on conduit and resistance vessel function in treated and untreated hypercholesterolaemic subjects," European Heart Journal, vol. 24, no. 18, pp. 1681-1689, 2003.

[280] C. R. Woodman, D. Ingram, J. Bonagura, and M. H. Laughlin, "Exercise training improves femoral artery blood flow 
responses to endothelium-dependent dilators in hypercholesterolemic pigs," The American Journal of Physiology-Heart and Circulatory Physiology, vol. 290, no. 6, pp. H2362-H2368, 2006.

[281] A.-L. Yang and H.-I. Chen, "Chronic exercise reduces adhesion molecules/iNOS expression and partially reverses vascular responsiveness in hypercholesterolemic rabbit aortae," Atherosclerosis, vol. 169, no. 1, pp. 11-17, 2003.

[282] C. Csonka, K. Kupai, P. Bencsik et al., "Cholesterol-enriched diet inhibits cardioprotection by ATP-sensitive $\mathrm{K}^{+}$channel activators cromakalim and diazoxide," American Journal of Physiology: Heart and Circulatory Physiology, vol. 306, no. 3, pp. H405-H413, 2014.

[283] P. Ferdinandy, Z. Szilvassy, M. Koltai, and L. Dux, "Ventricular overdrive pacing-induced preconditioning and noflow ischemia-induced preconditioning in isolated working rat hearts," Journal of Cardiovascular Pharmacology, vol. 25, no. 1, pp. 97-104, 1995.

[284] M. Pipicz, Z. V. Varga, K. Kupai et al., "Rapid ventricular pacinginduced postconditioning attenuates reperfusion injury: effects on peroxynitrite, RISK and SAFE pathways," British Journal of Pharmacology, vol. 172, no. 14, pp. 3472-3483, 2015.

[285] Z. Szilvassy, P. Ferdinandy, P. Bor, I. Jakab, J. Lonovics, and M. Koltai, "Ventricular overdrive pacing-induced anti-ischemic effect: a conscious rabbit model of preconditioning," American Journal of Physiology-Heart and Circulatory Physiology, vol. 266, no. 5, part 2, pp. H2033-H2041, 1994.

[286] C. Csonka, T. Csont, A. Ónody, and P. Ferdinandy, "Preconditioning decreases ischemia/reperfusion-induced peroxynitrite formation," Biochemical and Biophysical Research Communications, vol. 285, no. 5, pp. 1217-1219, 2001.

[287] E. Ferraro, A. M. Giammarioli, S. Chiandotto, I. Spoletini, and G. Rosano, "Exercise-induced skeletal muscle remodeling and metabolic adaptation: redox signaling and role of autophagy," Antioxidants and Redox Signaling, vol. 21, no. 1, pp. 154-176, 2014.

[288] L. Saso and O. Firuzi, "Pharmacological applications of antioxidants: lights and shadows," Current Drug Targets, vol. 15, no. 13, pp. 1177-1199, 2014. 


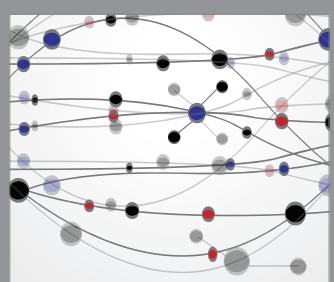

The Scientific World Journal
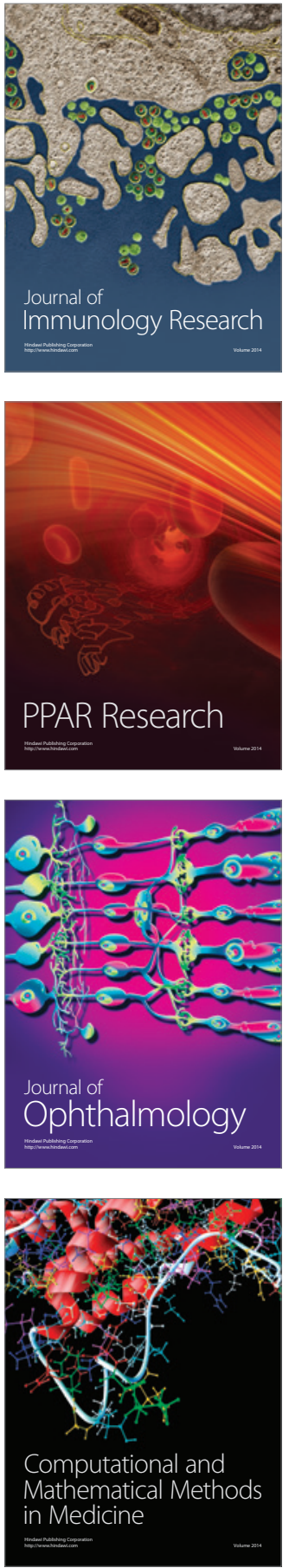

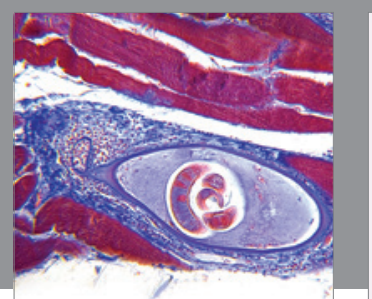

Gastroenterology Research and Practice

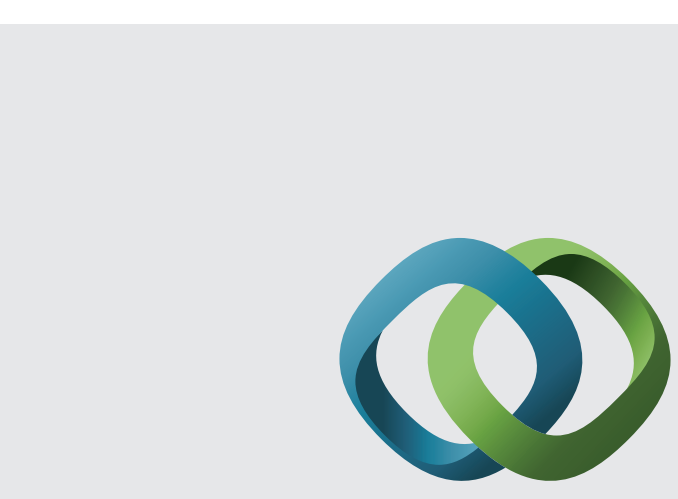

\section{Hindawi}

Submit your manuscripts at

http://www.hindawi.com
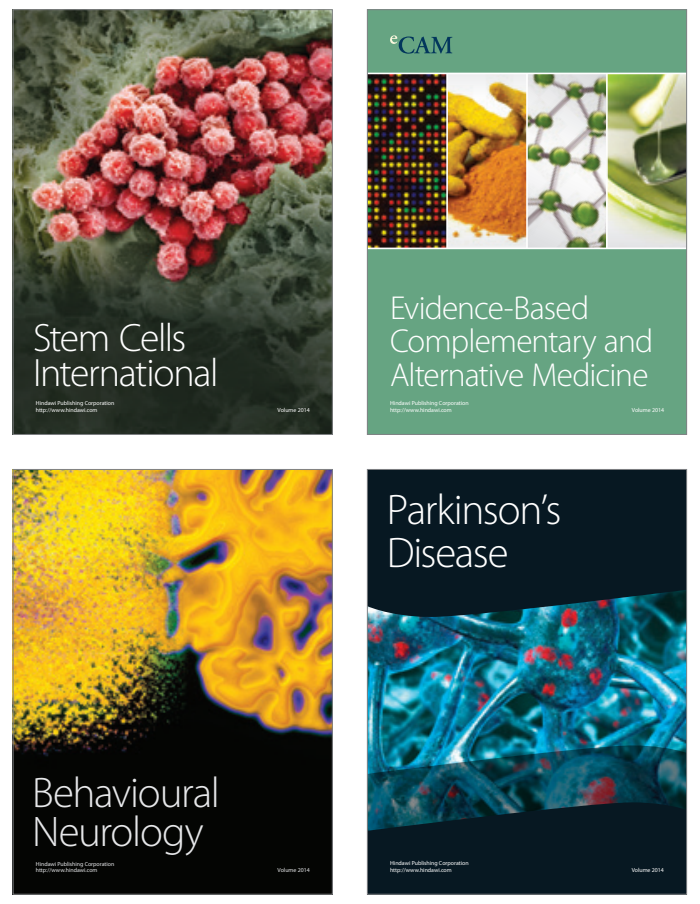
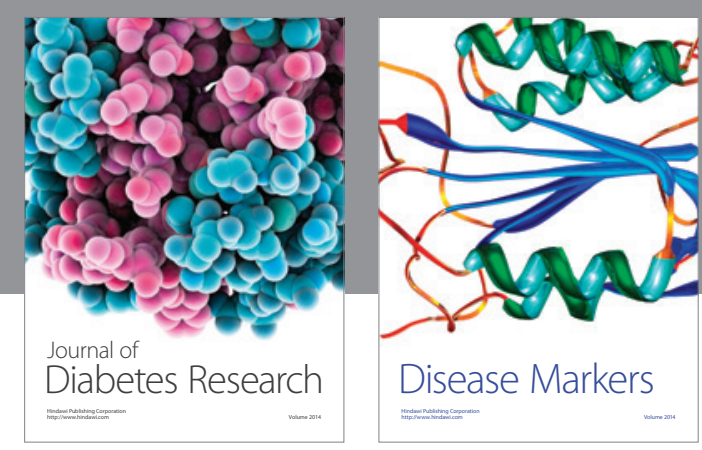

Disease Markers
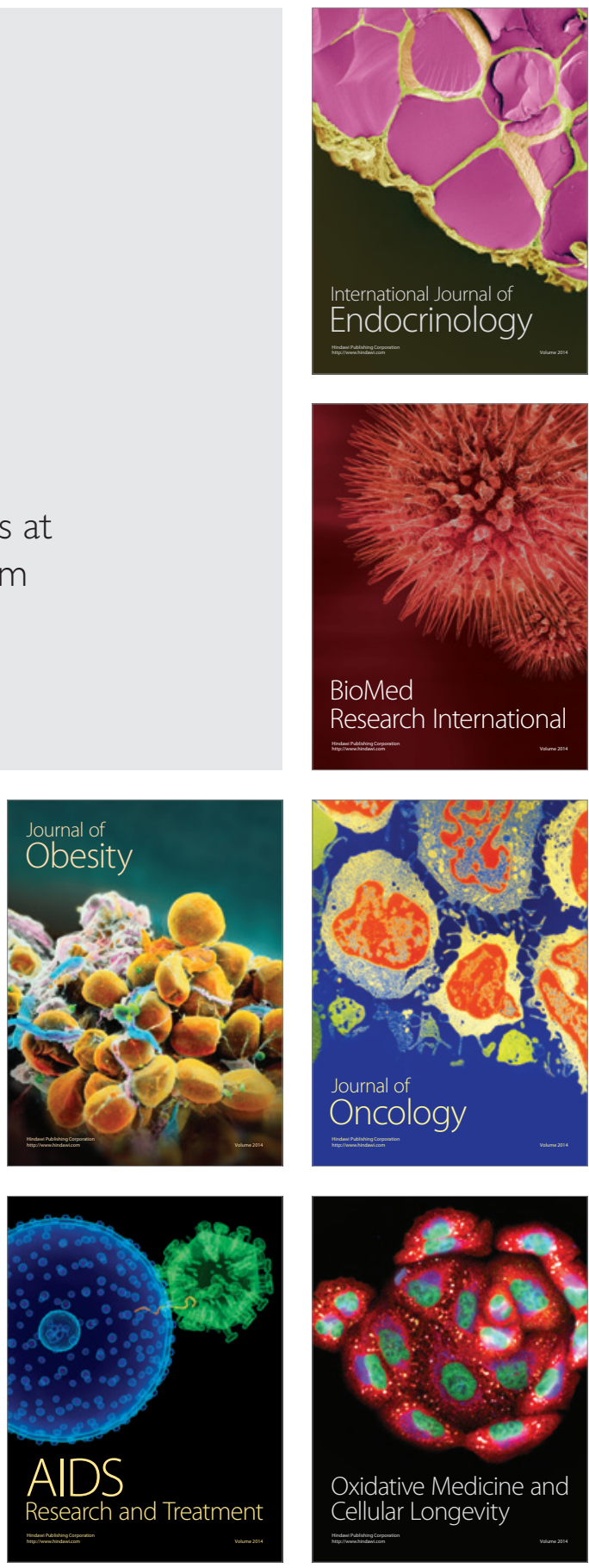